\title{
Physicochemical characterization and oxidative stability of fish oil-loaded electrosprayed capsules: Combined use of whey protein and carbohydrates as wall materials
}

García Moreno, Pedro Jesús; Pelayo, Andres; Yu, Sen; Busolo, María ; Chronakis, loannis S.; Jacobsen, Charlotte

Published in:

Journal of Food Engineering

Link to article, DOI:

10.1016/j.jfoodeng.2018.03.005

Publication date:

2018

Document Version

Peer reviewed version

Link back to DTU Orbit

Citation (APA):

García Moreno, P. J., Pelayo, A., Yu, S., Busolo, M., Chronakis, I. S., \& Jacobsen, C. (2018). Physicochemical characterization and oxidative stability of fish oil-loaded electrosprayed capsules: Combined use of whey protein and carbohydrates as wall materials. Journal of Food Engineering, 231, 42-53.

https://doi.org/10.1016/j.jfoodeng.2018.03.005

\section{General rights}

Copyright and moral rights for the publications made accessible in the public portal are retained by the authors and/or other copyright owners and it is a condition of accessing publications that users recognise and abide by the legal requirements associated with these rights.

- Users may download and print one copy of any publication from the public portal for the purpose of private study or research.

- You may not further distribute the material or use it for any profit-making activity or commercial gain

- You may freely distribute the URL identifying the publication in the public portal 


\section{Accepted Manuscript}

Physicochemical characterization and oxidative stability of fish oil-loaded electrosprayed capsules: Combined use of whey protein and carbohydrates as wall materials

Pedro J. García-Moreno, Andres Pelayo, Sen Yu, María Busolo, Jose M. Lagaron,

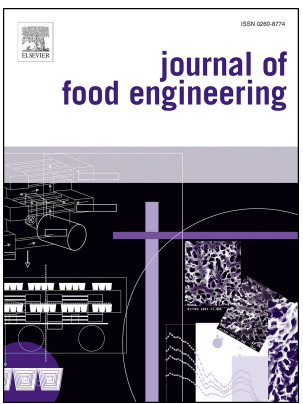
Ioannis S. Chronakis, Charlotte Jacobsen

PII:

$$
\text { S0260-8774(18)30108-0 }
$$

DOI:

$$
\text { 10.1016/j.jfoodeng.2018.03.005 }
$$

Reference: $\quad$ JFOE 9189

To appear in: Journal of Food Engineering

Received Date: 3 January 2018

Revised Date: 23 February 2018

Accepted Date: 9 March 2018

Please cite this article as: García-Moreno, P.J., Pelayo, A., Yu, S., Busolo, Marí., Lagaron, J.M., Chronakis, I.S., Jacobsen, C., Physicochemical characterization and oxidative stability of fish oil-loaded electrosprayed capsules: Combined use of whey protein and carbohydrates as wall materials, Journal of Food Engineering (2018), doi: 10.1016/j.jfoodeng.2018.03.005.

This is a PDF file of an unedited manuscript that has been accepted for publication. As a service to our customers we are providing this early version of the manuscript. The manuscript will undergo copyediting, typesetting, and review of the resulting proof before it is published in its final form. Please note that during the production process errors may be discovered which could affect the content, and all legal disclaimers that apply to the journal pertain. 


\section{Biopolymer} solution with omega-3 PUFA

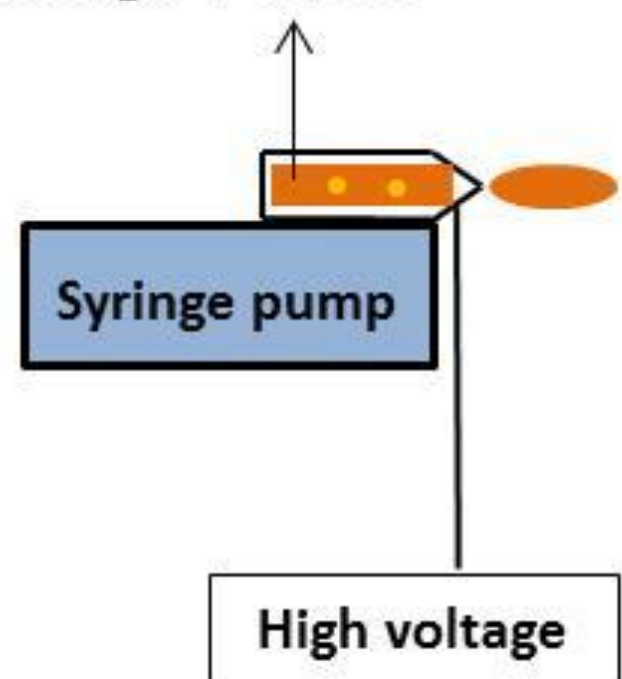

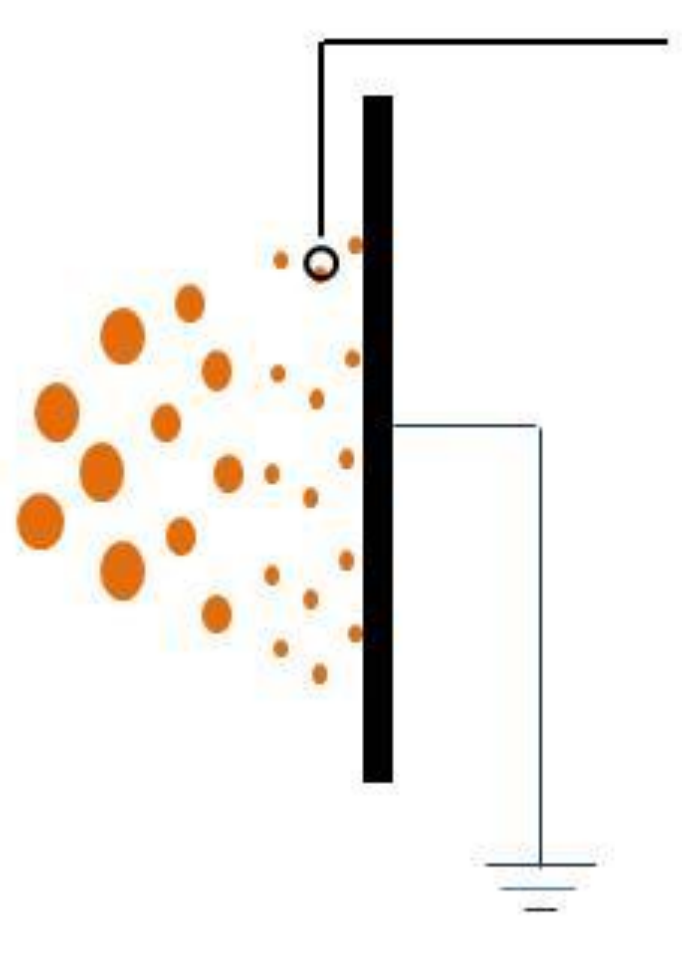

Electrosprayed capsule

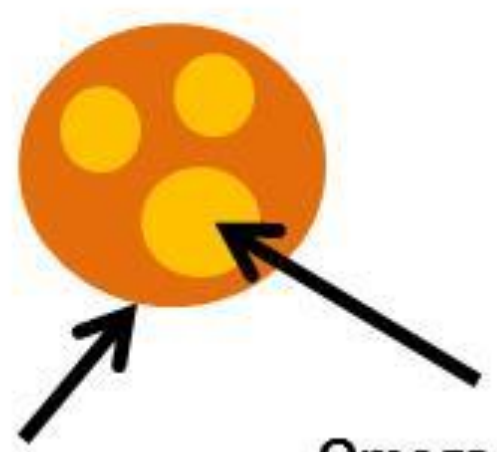

Biopolymer
Omega-3 PUFA 
1 Physicochemical characterization and oxidative stability of fish oil-loaded

2 electrosprayed capsules: combined use of whey protein and

3 carbohydrates as wall materials

4 Pedro J. García-Moreno ${ }^{a *}$, Andres Pelayo ${ }^{a}$, Sen $\mathrm{Yu}^{\mathrm{a}}$, María Busolo ${ }^{\text {b,c }}$, Jose M. Lagaron ${ }^{\text {b,c }}$, Ioannis S.

5 Chronakis $^{\mathrm{a}}$, Charlotte Jacobsen ${ }^{\mathrm{a}}$

$6 \quad{ }^{a}$ Division of Food Technology, National Food Institute, Technical University of Denmark, Denmark

$7 \quad{ }^{\mathrm{b}}$ Novel Materials and Nanotechnology Group, IATA-CSIC, Spain

$8 \quad{ }^{c}$ Bioinicia S.L., Spain

9 ABSTRACT

10 The encapsulation of fish oil in electrosprayed capsules using whey protein and carbohydrates

11 (pullulan and dextran or glucose syrup) mixtures as glassy wall materials was studied. Capsules with

12 fish oil emulsified by using only a rotor-stator emulsification exhibited higher oxidative stability than

13 capsules where the oil was emulsified by high-pressure homogenization. Moreover, glucose syrup

14 capsules (with a peroxide value, PV, of $19.7 \pm 4.4 \mathrm{meq} / \mathrm{kg}$ oil and a content of 1-penten-3-ol of

$15751.0 \pm 69.8 \mathrm{ng} / \mathrm{g}$ oil) were less oxidized than dextran capsules after 21 days of storage at $20^{\circ} \mathrm{C}(\mathrm{PV}$ of

$1624.9 \pm 0.4 \mathrm{meq} / \mathrm{kg}$ oil and 1-penten-3-ol of $1161.0 \pm 222.0 \mathrm{ng} / \mathrm{g}$ oil). This finding may be attributed to

17 differences in oxygen permeability between both types of capsules. These results indicated the

18 potential of both combinations of whey protein, pullulan, and dextran or glucose syrup as shell

19 materials for the encapsulation of omega-3 PUFA in nano-microcapsules obtained by electrospraying.

20 Keywords: Omega-3; Lipid oxidation; Electrospraying; Nano-microencapsulation; Dextran; Glucose

21 syrup

\section{INTRODUCTION}

23 Long chain omega-3 polyunsaturated fatty acids (PUFA) such as eicosapentaenoic (C20:5n-3) and 24 docosahexaenoic (C22:6n-3) acids, which are mainly extracted from fish, krill or microalgae biomass,

\footnotetext{
* Corresponding author. Tel: +45 935188 74; Fax: +45 458847 74; E-mail: pejeg@food.dtu.dk
} 
consumption of fish, krill or algae-based products by Western populations, the development of food fortified with omega-3 PUFA is still having an increasing interest for the food industry (GOED, 2015).

Nevertheless, these nutritionally beneficial lipids are highly prone to oxidation (i.e. due to their high content of bis-allylic hydrogens), which limit their successful incorporation into complex food systems (e.g. containing prooxidants such as metal ions) (Jacobsen, 2015).

In this regard, encapsulation of omega-3 PUFA is an approach generally used to avoid their oxidative deterioration (i.e. formation of secondary volatile oxidation products which are responsible for undesirable off-flavours) (García-Moreno et al., 2016). An emerging encapsulation technique for producing omega-3 nano-microencapsulates is electrospraying (Torres-Giner et al. 2010). Contrary to spray-drying (the most employed encapsulation technique), electrospraying can be carried out at room temperature, which should result in a better stability of thermo-sensitive bioactives (Lim, 2015). The process uses a high-voltage electrostatic field to charge the surface of a biopolymer solution droplet at the end of a capillary tube. When the surface tension of the droplet is overcome by the electric field, a charged jet is ejected from the tip of the Taylor cone (formed at the end of the capillary tube) to a grounded collector. Due to the low viscoelasticity of the biopolymer solution, the jet destabilize due to varicose instability forming fine highly charged droplets. On the way to the collector, the droplets are further disrupted due to electrostactic repulsion, which favors solvent evaporation resulting in solids particles (Ghorani \& Tucker, 2015). Electrosprayed encapsulates, which present high encapsulation efficiency and large surface-to-volume ratio, are of special interest for the food industry for the encapsulation of unstable bioactive compounds such as vitamins, probiotics, antioxidants and omega-3 fatty acids. Furthermore, due to their reduced size, these novel encapsulates exhibit a higher bioaccessibility than traditional capsules (Jacobsen et al., 2018).

To the best of the authors' knowledge, omega-3 fatty acids have only been encapsulated by electrospraying when using proteins such as zein, whey protein concentrate, soy protein isolate, and gelatin as shell material (Gómez-Mascaraque \& López-Rubio, 2016; Moomand \& Lim, 2015; TorresGiner et al., 2010). In the authors' previous work, the potential of dextran as a biopolymer shell to 
produce fish oil-loaded electrosprayed capsules was reported. However, further optimization of dextran solutions was required to improve the physical stability of the emulsion as well as the oil entrapment within the capsules (García-Moreno et al., 2017a). To this end, an interesting approach to be evaluated is the combination of both carbohydrates, which usually act as filler or matrix-forming material, and proteins, which exhibit emulsifying properties and are effective film-formers (Augustin \& Oliver, 2014). Dairy proteins (e.g. whey protein or casein), which also exhibit antioxidant properties (Adjonu et al. 2014), are usually combined with carbohydrates (i.e. glucose syrup, lactose, maltodextrin, starch) in order to obtain fish oil-loaded microencapsulates by spray-drying with enhanced properties (Encina et al. 2016). For instance, Aghbashlo et al. (2012) reported the production of microcapsules by spray-drying with significantly higher encapsulation efficiencies using mixtures of skim milk powder and lactose or sucrose ( $70 \%$ and $30 \%$, respectively) when compared to the use of only skim milk powder. Likewise, Ramakrishnan et al. (2013) found that the replacement of part of whey protein by maltodextrin as wall materials increased the oxidative stability of fish oil-loaded microcapsules. This was attributed to lower oxygen permeability of the shell material composed of maltodextrin. Furthermore, the incorporation of high-molecular weight carbohydrates (e.g. starch, maltodextrin, dextran) also increases the glass transition temperature of the wall material, which implies that the shell material will be in glassy state in a broader range of temperature (Schutyser et al. 2012). Glassy state of the protein-carbohydrate matrix is preferred to rubbery state due to its lower free volume, which restricts diffusion of oxygen and other prooxidants (i.e. trace of metals) enhancing the oxidative stability of the encapsulates ( $\mathrm{Hu}, 2016)$. In addition, the use of carbohydrates as encapsulating material, which are not digested in the stomach, will allow a more targeted delivery of omega-3 PUFA (e.g. in the small intestine where most absorption occurs) (Fathi et al. 2014).

In the light of the above, this work aimed at investigating the encapsulation of fish oil by electrospraying using combinations of whey protein and carbohydrates as biopolymers. Dextran and glucose syrup were selected as carbohydrates due to their appropriate properties to form electrosprayed capsules (García-Moreno et al., 2017a) and to their successful use in spray-dried capsules loaded with oils rich in omega-3 PUFA (Tamm et al. 2016), respectively. First, the influence 
of total concentration of biopolymers and carbohydrate to protein ratio on oil droplet size,

electrospraying flow rate, and morphology of the capsules was assessed in lab scale. Secondly, the approach used to emulsify the oil (i.e. high pressure homogenization or rotor-stator emulsification) in the optimized biopolymers solution was studied. Particularly, the ability to entrap the oil and the oil distribution of capsules produced by a high-throughput electrospraying process in pilot-plant scale was investigated. Finally, the protective effect against oxidative degradation of the different encapsulating matrices used was investigated during storage of the fish oil-loaded nano-microcapsules.

\section{MATERIALS AND METHODS}

\subsection{Materials}

Dextran (molecular weight $=70,000 \mathrm{Da}$, dextran70) was generously provided by Pharmacosmos A/S (Holbaek, Denmark). Glucose syrup (DE38, C*Dry 1934) was kindly provided by Cargill Germany GmbH (Krefeld, Germany). Pullulan (molecular weight =200,000 Da) was donated by Hayashibara Co., Ltd. (Okayama, Japan). Whey protein concentrate (WPC), under the commercial name of Lacprodan® DI-8090, was provided by ARLA Food Ingredients (Viby, Denmark). Citrem (citric acid ester without antioxidants) was provided from Danisco (Copenhagen, Denmark). The peroxide value (PV) of the citrem used was $2.3 \pm 0.1 \mathrm{meq} / \mathrm{kg}$ oil. Commercial cod liver oil was donated by Maritex A/S, subsidiary of TINE, BA (Sortland, Norway) and stored at $-40{ }^{\circ} \mathrm{C}$ until use. The fatty acid composition of the fish oil was determined by fatty acid methylation (AOCS, 1998a) followed by separation through GC (AOCS, 1998b). It was (major fatty acids only) as follows: C16:0, 9.5\%; $\mathrm{C} 16: 1,8.7 \%$; C18:1, 16.3\%; C20:1, 12.6\%; C20:5, 9.2\%; and C22:6, 11.4\%. The tocopherol content of the fish oil was: $\alpha$-tocopherol, $200 \pm 3 \mu \mathrm{g} / \mathrm{g}$ oil; $\beta$-tocopherol, $5 \pm 1 \mu \mathrm{g} / \mathrm{g}$ oil; $\gamma$-tocopherol, $96 \pm 3 \mu \mathrm{g} / \mathrm{g}$ oil; and $\delta$-tocopherol, $47 \pm 1 \mu \mathrm{g} / \mathrm{g}$ oil (AOCS, 1998c). PV of the fish oil used was $0.4 \pm 0.1 \mathrm{meq} / \mathrm{kg}$ oil. All other chemicals and solvents used were of analytical grade. 


\subsection{For optimization of capsules morphology in lab scale}

104 Electrospraying solutions containing fish oil (20 wt.\% with respect to biopolymer), WPC (1 wt.\%), 105 and carbohydrates (pullulan and dextran or glucose syrup) at different concentrations (1-5 wt.\% 106 pullulan and 15 or 20 wt.\% dextran or 15 wt.\% glucose syrup) were tested in lab scale in order to 107 optimize capsule morphology. First, WPC, pullulan, and dextran or glucose syrup were dissolved in 108 distilled water by stirring overnight at $500 \mathrm{rpm}$. Secondly, fish oil was added slowly to the 109 biopolymers solution during mixing at 16,000 rpm using an Ystral mixer (Ystral Gmbh, Ballrechten-

Dottingen, Germany). The fish oil was added during the first minute of mixing, and the total mixing time was 3 min. Further homogenization was done on a microfluidizer (M110L Microfluidics,

Newton, MA, USA) equipped with a ceramic interaction chamber (CIXC, F20Y, internal dimension $75 \mu \mathrm{m})$. Emulsions were homogenized at a pressure of 9000 psi, running 3 passes. Samples were used immediately after production for electrospraying processing in lab scale and for droplet size analysis.

\subsection{For production in pilot plant}

Biopolymer solutions containing fish oil for processing in pilot plant were prepared following two different approaches to emulsify the oil. In the first approach, fish oil was emulsified by using high pressure homogenization. Briefly, pullulan and dextran or glucose syrup were dissolved in distilled water under constant stirring (500 rpm) at room temperature. Fish oil was added as $10 \mathrm{wt} \%$ fish oilin-water emulsion stabilized with 1 wt.\% WPC and 1 wt.\% citrem at $\mathrm{pH} 7$. The homogenization process was carried out by using an Ystral mixer followed by microfluidizer (M110L Microfluidics, Newton, MA, USA) as described above. The biopolymer solutions and the fish oil-in-water emulsion were mixed under nitrogen atmosphere by using magnetic stirring $(500 \mathrm{rpm})$ for $30 \mathrm{~min}$ at $5{ }^{\circ} \mathrm{C}$ in the dark. Finally, the resulting emulsion was passed 3 times through microfluidizer (M110L Microfluidics, Newton, MA, USA) at a pressure of 9,000 psi. The resulting electrospraying solutions contained $20 \mathrm{wt} . \%$ fish oil (with respect to biopolymer). The samples were subsequently characterized for droplet size analysis and dried by electrospraying assisted by pressurized air using the Fluidnatek ${ }^{\mathrm{TM}}$ LE500 Capsultek pilot tool by Bioinicia S.L. (Valencia, Spain). Dextran solution was 
130 samples were kept at $4{ }^{\circ} \mathrm{C}$ until electrospraying was carried out.

131 In the second approach, fish oil was emulsified by only using a rotor-stator emulsification. In brief, 132 carbohydrates (pullulan and dextran or glucose syrup) together with WPC were dissolved in distilled 133 water and stirred overnight using magnetic stirrer at $500 \mathrm{rpm}$. Then, the biopolymer solution was 134 passed through microfluidizer (M110L Microfluidics, Newton, MA, USA) 3 times at 9,000 psi. 135 Citrem and fish oil were added slowly, under nitrogen atmosphere, into the resulting biopolymer 136 solution during mixing at 17,500 rpm using an Ultraturrax T-25 homogenenizer (IKA, Staufen, 137 Germany). The fish oil was added during the first 5 min of mixing, and the total mixing time was 8 138 min. The resulting electrospraying solutions also contained 20 wt.\% fish oil (with respect to 139 biopolymer). Samples were used immediately after production for processing in pilot plant equipment 140 LE500 Capsultek (Bioinicia and Fluidnatek®, Valencia, Spain).

\section{$141 \quad 2.3$ Droplet size distribution of solutions}

142 Droplet sizes were measured by laser diffraction in a Mastersizer 2000 (Malvern Instruments, Ltd., 143 Worcestershire, UK). Solutions were diluted in recirculating water (3000 rpm), until it reached an 144 obscuration of $12 \%$. The refractive indices of sunflower oil (1.469) and water (1.330) were used as 145 particle and dispersant, respectively. Results were given in surface area mean diameter $\left(\mathrm{D}_{3,2}\right)$ and $90 \%$ 146 percentile $\left(\mathrm{d}_{0.9}\right)$. Measurements were made in triplicate.

\subsection{Electrospraying process}

148 In lab scale, the electrospraying process was carried out at room temperature by adding the biopolymer 149 solutions containing the fish oil to a syringe, which was placed in a syringe pump (New Era Pump 150 Systems, Inc., USA). A 16 G needle (Proto Advantage, Canada) was used. A high-voltage electrostatic 151 field was applied between the spinneret of the syringe and a $15 \times 15 \mathrm{~cm}$ collector plate made of 152 stainless by using a high voltage power supply (Gamma High Voltage Research, USA). An horizontal 153 conformation was selected and the distance between the syringe tip and the collector plate was $15 \mathrm{~cm}$. 
were optimized in order to stabilize the Taylor cone and avoid dripping or droplets in the collector.

156 In pilot plant scale, biopolymers solutions containing fish oil were subjected to electrospraying assisted by pressurized air using the patent pending Fluidnatek ${ }^{\mathrm{TM}}$ LE500 Capsultek pilot tool 158 (Bioinicia S.L., Valencia, Spain). Solutions were processed using flowrates between 1.5 and 1.8 $159 \mathrm{~mL} / \mathrm{min}$ and voltages between 10 and $15 \mathrm{kV}$. The collection of the encapsulated powder was carried 160 out in a grounded cyclonic collector as a free flowing powder. Temperature was maintained at $24{ }^{\circ} \mathrm{C}$ 161 and relative humidity at $40 \%$. The production batches had a duration of $40 \mathrm{~min}$. The powder collected in the different batches (for the same type of capsule) were blended together in order to have a 163 homogeneous final sample. Dextran and glucose syrup capsules were coded as D-HPH or G-HPH and 164 D-RSE or G-RSE when the oil was emulsified by using high-pressure homogenization of rotor-stator 165 emulsification, respectively.

\subsection{Characterization of electrosprayed capsules}

\subsubsection{Morphology}

168 The morphology of the different types of electrosprayed capsules produced was investigated using 169 scanning electron microscopy (SEM) (Phenom Pro, Phenom-World B.V., Eindhoven, The Netherlands). 170 Approximately $0.5 \times 0.5 \mathrm{~cm}$ of the capsules aluminium sheet was placed on carbon tape and sputter 171 coated with gold, 8 s, 40 mA utilizing a Q150T Quorum Coater (Quorum Technologies Ltd, East Sussex, 172 UK). The capsule diameter distribution was determined from the micrographs by using the open 173 source image processing program ImageJ (National Institutes of Health). One hundred random 174 capsules were measured.

\section{$175 \quad$ 2.5.2 Encapsulation efficiency (EE)}

176 The efficiency of the encapsulation was determined by measuring the non-encapsulated oil, which was 177 extracted according to Westergaard (2004) with some modifications. Briefly, $1 \mathrm{~g}$ of electrosprayed 178 capsules was immersed in $5 \mathrm{~mL}$ heptane and shaken at $100 \mathrm{rpm}$ for $2 \mathrm{~min}$. Then, the suspension was

179 filtered and the retained solid washed three times with $2 \mathrm{~mL}$ heptane. From the recovered liquid, the 180 heptane was evaporated and the amount of extracted oil was weighted. Analyses were carried out in 
182 capsules.

183

\subsubsection{Oil distribution}

The droplet size distribution of the fish oil-loaded electrosprayed capsules after re-dispersion in distilled water was measured as previously described in section 2.3. For that purpose, $1 \mathrm{~g}$ of capsules was dissolved in $15 \mathrm{~mL}$ of distilled water at room temperature under magnetic stirring (100 rpm) for $30 \mathrm{~min}$. The resulting dispersion was filtered in order to remove the possible rest of capsules.

Moreover, oil distribution in the capsules was also analyzed by fluorescence microscopy. Electrospraying solutions were stained with Nile red and fluorescein isothiocyanate to visualize fish oil and WPC, respectively. The nano-microcapsules were directly electrosprayed in a coverslip and then covered with a glass slide. Then, the distribution of fish oil and WPC within the nanomicrocapsules was analyzed with a fluorescence microscope Olympus BX53 fitted with a Retiga-6000 monochrome camera (Olympus Danmark A/S, Ballerup, Denmark). Fluorescence was measured after irradiation at $580 \mathrm{~nm}$ or $488 \mathrm{~nm}$. Images were captures using the Olympus cellSens Dimension V1 software and further processed in Adobe Photoshop CS6.

\subsubsection{Glass transition temperature}

Glass transition temperature $\left(\mathrm{T}_{\mathrm{g}}\right.$ ) of the capsules was determined using a Discovery DSC (TA Instruments, New Castle, USA). For each scan, 2-5 mg of capsules were hermetically sealed in an aluminium pan and tested again and identical empty pan. Samples were cooled and held isothermally at $-80{ }^{\circ} \mathrm{C}$ for $10 \mathrm{~min}$, then heated to $200{ }^{\circ} \mathrm{C}$ with a ramp rate of $10{ }^{\circ} \mathrm{C} / \mathrm{min}$ under nitrogen atmosphere (50 mL/min). TRIOS software (TA Instruments, New Castle, USA) was used to determined $\mathrm{T}_{\mathrm{g}}$ from the midpoint of the heat flow derivative.

\subsubsection{Oxidative stability}

For lipid oxidation measurements, immediately after receiving the samples from Bioinicia and Fluidnatek ${ }^{\circledR}$ (Valencia, Spain), the capsules were stored in $10 \mathrm{~mL}$ vial at $20{ }^{\circ} \mathrm{C}$ in the dark for 21 days. Each vial contained approximately $2.2 \mathrm{~g}$ of capsules in order to maintain a similar headspace. Samples were taken at day $0,3,8,14$ and 21 for analysis. 
ATR-FTIR spectra of the capsules were obtained by using Spectrum 100 FT-IR Spectrometer

(PerkinElmer, Waltham, USA). Approximately $10 \mathrm{mg}$ of capsules were placed on top of the

ZnSe/diamond crystal and good contact was assured by using the Universal ATR Sampling Accessory

(PerkinElmer, Waltham, USA). All spectra were recorded within the wavenumber range of 4000-600

$213 \mathrm{~cm}^{-1}$ by averaging 20 scans at $4 \mathrm{~cm}^{-1}$ resolution. Measurements were performed in triplicate. Results were normalized to the initial intensity for a better comparison among the different capsules.

\subsubsection{Determination of oil content and peroxide value}

Oil was extracted from approximately $0.5 \mathrm{~g}$ of capsules according to Bligh and Dyer method using a reduced amount of the chloroform/methanol (1:1, wt.\%) solvent (Bligh \& Dyer, 1959). Two extractions were made from each sample. Peroxide value was determined on lipid extracts using the colorimetric ferric-thiocyanate method at $500 \mathrm{~nm}$ as described by Shantha and Decker (1994). Results were expressed as milliequivalents of peroxides per $\mathrm{kg}$ of oil.

\subsubsection{Volatiles secondary oxidation products - Dynamic headspace GC-MS}

Approximately $0.4 \mathrm{~g}$ of capsules and $10 \mathrm{mg}$ internal standard (4-methyl-1-pentanol, $30 \mu \mathrm{g} / \mathrm{g}$ water)

were weighted out in a $100 \mathrm{~mL}$ purge bottle, to which $5 \mathrm{~mL}$ of distilled water and $1 \mathrm{~mL}$ antifoam

(Synperonic $800 \mu \mathrm{L} / \mathrm{L}$ water) were added. The bottle was heated to $45^{\circ} \mathrm{C}$ in a water bath while purging with nitrogen (flow $250 \mathrm{~mL} / \mathrm{min}, 30 \mathrm{~min}$ ). Volatile secondary oxidation products were trapped on

Tenax GR tubes. The volatiles were desorbed again by heating $\left(200^{\circ} \mathrm{C}\right)$ in an Automatic Thermal

Desorber (ATD-400, Perkin Elmer, Norwalk, CN), cryofocused on a cold trap $\left(-30^{\circ} \mathrm{C}\right)$, released again $\left(220^{\circ} \mathrm{C}\right)$, and led to a gas chromatograph (HP 5890IIA, Hewlett Packard, Palo Alto, CA, USA;

Column: DB-1701, $30 \mathrm{~m}$ x $0.25 \mathrm{~mm}$ x $1.0 \mu \mathrm{m}$; J\&W Scientific, CA, USA). The oven program had an 230 initial temperature of $45^{\circ} \mathrm{C}$ for $5 \mathrm{~min}$, increasing with $1.5^{\circ} \mathrm{C} / \mathrm{min}$ until $55^{\circ} \mathrm{C}$, with $2.5^{\circ} \mathrm{C} / \mathrm{min}$ until $23190^{\circ} \mathrm{C}$, and with $12.0^{\circ} \mathrm{C} / \mathrm{min}$ until $220^{\circ} \mathrm{C}$, where the temperature was kept for $4 \mathrm{~min}$. The individual 232 compounds were analyzed by mass-spectrometry (HP 5972 mass-selective detector, Agilent 233 Technologies, USA; electron ionization mode, $70 \mathrm{eV}$; mass to charge ratio scan between 30 and 250). 234 The individual compounds were identified by both MS-library searches (Wiley $138 \mathrm{~K}$, John Wiley and 
The external standards employed were 2-ethyl-furan, 1-penten-3-one, pentanal, 1-penten-3-ol, (E)-2pentenal, hexanal, 2-hexenal, heptanal, 2-pentyl-furan, $(E, E)-2,4$-heptadienal, and nonanal (SigmaAldrich, Brøndby, Denmark). Samples were analyzed in triplicate.

\subsection{Statistical analysis}

Statgraphics Centurion XV (Statistical Graphics Corp., Rockville, MD, USA) was used for data analysis. Data were expressed as mean \pm standard deviation. Firstly, multiple sample comparison analysis was performed to identify significant differences between samples. Secondly, mean values were compared by using the Tukey's test. Differences between means were considered significant at $\mathrm{p}$ $<0.05$.

\section{RESULTS AND DISCUSSION}

\subsection{Optimization of biopolymer solutions}

The properties of the biopolymer solutions (e.g. viscosity, conductivity, and surface tension) together with the processing variables (i.e. voltage and flowrate) have a high influence on the electrospraying process (e.g. stability of Taylor cone and morphology of capsules). The solution properties are mainly determined by the type of biopolymers used (i.e. molecular weight and concentration) as well as by the type of solvent (Drosou et al. 2017). Taking this into account, the composition of dextran and glucose syrup solutions containing fish oil were first optimized in the lab before scaling-up. Pullulan was added to both type of solutions as thickening agent since it allowed to increase the stability of the Taylor cone, avoiding dripping and droplets in the collector while also working at higher flow rate. Both high solid content in solutions (wt.\% of biopolymers and oil) as well as high flow rate are desired 256 in order to increase the throughput of electrospraying process. With a similar objective, Pérez-Masiá et al. (2014) employed gums (e.g. guar and xanthan gum) in order to increase the viscosity of carbohydrate (i.e. resistant starch or maltodextrin) solutions, which allowed the formation of capsules by electrospraying. However, these authors also observed the formation of a continuous film together with the capsules, which was attributed to the ability of gums to retain water leading to an incomplete 
which may be attributed to a lower retention of water by pullulan when compared to gum facilitating the drying process.

Fig. 1 shows the morphology of the nano-microstructures obtained when varying the concentration of pullulan (1-2 wt.\%) and dextran (15-20 wt.\%) in an aqueous solution also containing $1 \mathrm{wt} . \% \mathrm{WPC}$ and 20 wt. $\%$ of emulsified fish oil (with respect to biopolymers). It was observed that when using 2 wt.\% pullulan and 20 wt.\% dextran, some capsules were obtained, but they were interconnected with abundant fibers (Fig. 1a). Nevertheless, reducing the concentration of biopolymers, especially pullulan which has been reported to have an extraordinary spinnability leading to fiber formation (GarcíaMoreno et al. 2017), considerably decreased the polymer chain entanglements avoiding the formation of fibril defects. For instance, decreasing the concentration of dextran to 15 wt. $\%$ ( 2 wt.\% pullulan) significantly reduced the formation of fibers (Fig. 1b). Likewise, fibers were almost not observed when reducing the content of pullulan to $1 \mathrm{wt} . \%$ (20 wt.\% dextran) (Fig. 1c), and no fibril defects were found in the capsules obtained when using a solution of $1 \mathrm{wt} . \%$ pullulan and $15 \mathrm{wt} . \%$ dextran (Fig. 1d). Capsules are preferred to fibers as delivery systems due to their ability to easily disperse in the food matrix (Pérez-Masiá et al. 2015). The dispersion of fibers is more challenging due to their continuous and interconnected morphology. As expected, decreasing pullulan concentration from 2 to 1 wt.\% slightly reduced the electrospraying flow rate (from 0.012 to $0.010 \mathrm{~mL} / \mathrm{min}$ ) (Table 1). Moreover, decreasing dextran concentration in the solution led to a significantly $(\mathrm{p}<0.05)$ more effective droplet disruption in the high pressure homogenizer (Table 1), mainly due to a lower viscosity of the solution. Smaller droplet sizes are desired in order to enhance the entrapment of the oil within the wall material matrix (Ramakrishnan et al. 2013).

283 For the glucose syrup solution, only the pullulan content was varied from 2 to 5 wt. $\%$, while the content of the glucose syrup was kept constant at $15 \mathrm{wt} . \%$ in order to have the same concentration as for dextran in the previous solution. Fig. 2 shows that only capsules were obtained when using either 2 or 4 wt.\% pullulan (Fig. 2a,b), whereas fibril defects appeared between the capsules due to more polymer chain entanglements when increasing pullulan concentration to $5 \mathrm{wt} \%$ (Fig. 2c). In order to 
increasing pullulan content from 2 to $4 \mathrm{wt}$ \% led to a significantly $(\mathrm{p}<0.05)$ larger droplet size, it also allowed a considerable improvement of the electrospraying flow rate (from 0.003 to $0.007 \mathrm{~mL} / \mathrm{min}$ )

(Table 1). It is worth noting the lower electrospraying flow rate for the glucose syrup solution when compared to the dextran solution, despite the higher content of pullulan employed (4 vs. 1 wt.\%, respectively). This might be attributed to the lower number of polymer chain entanglements in the glucose solution compared to dextran, as a consequence of the different molecular weights of the carbohydrates used (70 kDa for dextran and $12.5 \mathrm{kDa}$ for glucose syrup, as reported by Pharmacosmos A/S and Cargill Germany GmbH respectively) (Pérez-Masiá et al., 2014).

Finally, the replacement of half of the WPC used as emulsifier by an efficient surfactant such as citrem led to significant $(p<0.05)$ smaller oil droplet size when compared to electrospraying solutions containing only WPC, both in dextran and glucose syrup solutions (Table 1). This should favor both the physical stability of the solution until drying as well as the efficiency of the encapsulation process. Therefore, taken together, optimum solutions for further production in pilot-plant scale were selected as: i) 0.5 wt. $\%$ WPC, 0.5 wt.\% citrem, 1 wt.\% pullulan, and 15 wt. $\%$ dextran, and ii) 0.5 wt.\% WPC, 0.5 wt. $\%$ citrem, 4 wt.\% pullulan, and 15 wt. $\%$ glucose syrup.

\subsection{Physicochemical properties of the capsules}

\subsubsection{Morphology}

Fig. 3 shows that the capsules obtained in pilot-plant for the two types of carbohydrates (dextran or glucose syrup) and for the two approaches used to emulsify the oil (high pressure homogenization or rotor-stator emulsification) had a spherical shape with no fibril defects. In general, dextran capsules 309 showed no clear cracks or fissures, although small holes could be observed at their surface, especially 310 for capsules where the oil was incorporated by using high pressure homogenization (Fig. 3a,b). 311 Glucose syrup capsules presented a less smooth surface when compared to dextran capsules, as 312 indicated by the presence of some fissures and larger holes on the surface. This phenomenon was also 313 observed to a higher extent for capsules with oil emulsified by high pressure homogenization (Fig. 
section 3.2.2.

316 The four type of capsules produced presented a broad size range, varying from submicron particles to microcapsules up to $10 \mu \mathrm{m}$ (Fig. 3). Nonetheless, most of the capsules (approximately $70 \%$ ) had a size lower than $3 \mu \mathrm{m}$. Although no significant differences were observed between G-HPH and G-RSE capsules, D-HPH capsules showed a larger diameter when compared D-RSE capsules (Fig. 3a,b). This may be attributed to the higher flow rate and voltage used to produce D-RSE capsules compared to D-HPH (1.8 vs. $1.5 \mathrm{~mL} / \mathrm{min}$ and 15 vs. $10 \mathrm{kV}$ ), which favoured the formation of satellite droplets (Hartman et al. 2000).

Overall, the capsules produced in pilot-plant presented a larger diameter when compared to capsules produced in lab scale, where approximately $60-70 \%$ of the capsules were below $1 \mu \mathrm{m}$ (see Fig. S1 of the Supplementary material). In order to increase throughput, in pilot-plant electrospraying the solution is impelled into the electric field by pressurized air, hence the solution droplet size cannot be reduced to the level obtained by conventional electrospraying process in lab scale. In any case, the electrosprayed capsules obtained in this study showed a reduced size compared to microcapsules loaded with fish oil and obtained by spray-drying, which have been reported to have diameters between 14.2-18.1 $\mu \mathrm{m}$ (Drusch, 2007) or 17.9-23.0 $\mu \mathrm{m}$ (Carneiro et al. 2013). Capsules with a reduced size are preferred for incorporation into a food matrix since they might be easier to disperse and could have a lower effect on product quality (e.g. texture). Moreover, particles with a lower diameter present a larger specific surface area, which might enhance the release profile of the bioactive compound. On the other hand, a larger surface-to-volume ratio also implies an increase of the contact surface between lipids and prooxidants, which negatively affects oxidative stability of the capsules (Jacobsen et al. 2018).

\subsubsection{Oil encapsulation and distribution}

338 Oil encapsulation and distribution within the shell material determines the accessibility of prooxidants to the oil as well as the available contact surface, which might have a great importance on the oxidative stability of the capsules (Drusch \& Berg, 2008). The longer time spent before the drying of 
rotor-stator emulsification (which were produced in situ in the electrospraying pilot-plat) explain the 343 significantly $(\mathrm{p}<0.05)$ higher $\mathrm{D}_{3,2}$ values of the reconstituted capsules obtained from the former 344 emulsions (Table 2). However, the correlation between droplet size and EE is not clear since EE 345 values were higher for the capsules containing oil emulsified by rotor-stator emulsification, besides 346 the significantly higher $\mathrm{D}_{0,9}$ value of these capsules (Table 2).

347 Dextran capsules showed significantly higher EE values than glucose syrup capsules for both type of 348 emulsification approaches, which correlated well with the lower $\mathrm{D}_{3,2}$ and $\mathrm{D}_{0,9}$ values of the dextran 349 capsules when compared to glucose syrup capsules (Table 2). Glucose syrup nano-microcapsules 350 presented large holes on the surface (Fig. 3a,b), which in fish oil-loaded microcapsules produced by 351 spray-drying has been related to the presence of non-encapsulated oil droplets (Drusch \& Berg, 2008). 352 Fig. 4 shows how fish oil is distributed in electrosprayed nano-microcapsules containing oil emulsified 353 by high-pressure homogenization and produced in lab scale. Fig.4a1,b1 show the location of fish oil 354 (in red) and Fig.4a2,b2 show the location of WPC (in green). It was observed that oil droplets were 355 entrapped within the shell material but both dextran and glucose syrup capsules also presented non356 encapsulated oil, since oil droplets were located at the capsule surface or very close to the surface 357 (marked as white arrows in Fig. 4-a3,b3). In any case, it is worth noting that the EE values obtained 358 for fish oil-loaded dextran and glucose syrup nano-microcapsules (20 wt.\% oil load) were higher than 359 EE values reported for gelatin, whey protein concentrate and soy protein isolate nano-microcapsules 360 loaded with $10 \mathrm{wt} . \%$ of $\alpha$-linoleic acid (ALA) and produced by electrospraying (23-67 \% EE based on 361 intact ALA) (Gómez-Mascaraque \& López-Rubio, 2016). Nevertheless, they were in the same range 362 as fish oil-loaded capsules (40 wt.\% oil load) produced by spray-drying using caseinate and glucose 363 syrup (13 wt.\% extractable oil) or sugar beet pectin and glucose syrup (25.9 wt.\% of extractable oil) as 364 wall materials (Drusch et al., 2007).

\subsubsection{Glass transition temperature}

366 A glassy shell is desired in order to prevent oxygen diffusion through the capsule and to avoid caking 367 (Huang et al., 2014). Fig. 5 shows the DSC heating curves of the nano-microcapsules containing oil 
capsules, three endothermic peaks were found in the range from $-75^{\circ} \mathrm{C}$ to $10{ }^{\circ} \mathrm{C}$, which indicated the range of melting temperature for the different triglycerides in the fish oil. In the case of dextran $\mathrm{T}_{\mathrm{g}}$ at $94.2{ }^{\circ} \mathrm{C}$ (Fig. 5b). This difference between both types of capsules could be explained by the different $\mathrm{T}_{\mathrm{g}}$ of the carbohydrates used as wall materials. The dextran employed had a $\mathrm{T}_{\mathrm{g}}$ at $143.3{ }^{\circ} \mathrm{C}$, whereas the $\mathrm{T}_{\mathrm{g}}$ of the glucose syrup used was at $59.3{ }^{\circ} \mathrm{C}$ (see Fig. S2ab of the Supplementary material). These values differed from those previously reported for glucose syrup (DE36) and dextran $\left(74.3 \mathrm{kDa}\right.$ ) in the literature, $\mathrm{T}_{\mathrm{g}}$ at $31^{\circ} \mathrm{C}$ and $223{ }^{\circ} \mathrm{C}$ respectively (Drusch et al., 2007; Scandola et al. 1991). This might be due to the different type of biopolymer used (Mw and DE) and to possible differences in their residual water levels. In regard to pullulan, no $T_{g}$ was found in the range of temperature studied (see Fig. S2c of the Supplementary material). This is in line with the findings of Scandola et al. (1991), who did not observe any melting or $\mathrm{T}_{\mathrm{g}}$ for pullulan below its thermal decomposition temperature $\left(300{ }^{\circ} \mathrm{C}\right)$. It is worth mentioning that fish oil-loaded dextran and glucose capsules had a higher $\mathrm{T}_{\mathrm{g}}$ than skim milk powder and lactose $\left(\mathrm{T}_{\mathrm{g}}\right.$ at $\left.67{ }^{\circ} \mathrm{C}\right)$ or sucrose $\left(\mathrm{T}_{\mathrm{g}}\right.$ at $\left.50{ }^{\circ} \mathrm{C}\right)$ capsules containing fish oil and obtained by spray-drying (Aghbashlo et al., 2012).

\subsection{Oxidative stability of capsules}

\subsubsection{ATR-FTIR}

Firstly, and in accordance with previous studies (Gómez-Mascaraque \& López-Rubio, 2016; Torres-

Giner et al., 2010), the oxidative stability of the capsules was evaluated by ATR-FTIR. Many of the characteristics bands of fish oil overlapped with the infrared bands of the biopolymers used as wall materials (WPC, dextran, pullulan and glucose syrup). Nevertheless, the characteristic absorption band 391 of omega-3 PUFA at $3012 \mathrm{~cm}^{-1}$, which corresponds to the stretching of cis-alkene (-HC=CH-) groups 392 (Guillén \& Cabo, 1999), did not overlap with the vibrational modes of the protein and carbohydrates 393 employed (see Fig. S3 of the Supplementary material). As a result, the intensity of this band, which 394 indicated the disappearance or not of cis double bonds due to oxidation, was monitored during the 
capsules did not significantly decrease during storage, apart from D-HPH capsules which slightly decreased at day 21. This may imply that the capsules were not oxidized during storage due to the fact that the cis-alkene groups were not degraded. Nonetheless, it should be noted that, although the generation of hydroperoxides changes the conformation of some double bonds due to the formation of conjugated cis-/trans- or trans-/cis- dienes, a reduction in the frequency of the band at $3006-3012 \mathrm{~cm}^{-1}$ is generally associated with advanced stages of lipid oxidation (Guillén \& Cabo, 2000). However, and opposite to what we observed, other studies have reported a decrease in the intensity of this band during storage. For instance, Moomand and Lim (2014) observed a reduction of the absorption at 3012

$\mathrm{cm}^{-1}$ for ultrathin zein fibers containing fish oil during storage at different temperatures $(4,25$, and 60

${ }^{\circ} \mathrm{C}$ ) for 14 days. Likewise, Gomez-Mascaraque and López-Rubio (2016) found a reduction in the intensity of the same band for gelatin, whey protein, and soy protein electrosprayed capsules loaded with ALA during storage at $80^{\circ} \mathrm{C}$ for 5 days.

\subsubsection{PV and volatiles}

The oxidative stability of the capsules was further evaluated by measuring the formation of primary and secondary volatile oxidation compounds. Fig. $6 \mathrm{~b}$ shows the PV of the different capsules during storage. It was observed that the PV of the fish oil-loaded capsules after production, which ranged 412 from $7.4 \pm 0.6$ to $10.3 \pm 0.1 \mathrm{meq} / \mathrm{kg}$ oil, was significantly higher than the PV of the initial fish oil $413(0.4 \pm 0.1 \mathrm{meq} / \mathrm{kg}$ oil $)$. This might be attributed to lipid oxidation during: i) emulsion preparation due to oxygen inclusion and increase in specific surface area (as reported by Serfert et al., 2009), and ii) encapsulation process as a result of the exposure of the surface oil to atmospheric air during 416 production (as reported by Drusch et al., 2006).

417 Although the PV of the capsules at day 0 was not significantly affected by the carbohydrate or oil 418 emulsification approach used, different trends in hydroperoxides content were observed during storage 419 for the capsules studied (Fig. 6b). Independently of the carbohydrate used, a longer lag phase was 420 found for the capsules with oil emulsified by rotor-stator equipment when compared to those 421 containing oil emulsified by high-pressure homogenization ( 8 days vs. 3 days). Furthermore, the PV of 
storage than the PV of the capsules with oil incorporated by rotor-stator emulsification (apart from glucose syrup capsules at day 21). PV of the electrosprayed capsules with oil (20 wt.\%) emulsified only by rotor-stator equipment was similar to those reported by Morales-Medina et al. (2016) for microcapsules containing 14 wt.\% fish oil and produced by spray-drying using fish protein hydrolysates and glucose syrup as wall materials (PV of ca. $20 \mathrm{meq} / \mathrm{kg}$ oil after 20 days storage at 20 ${ }^{\circ} \mathrm{C}$ ); and lower than those found by Drusch \& Berg (2008) for spray-dried microcapsules loaded with 30 wt.\% fish oil and containing n-OSA starch and glucose syrup as shell materials (PV of ca. 30 meq/kg oil after 21 days storage at $\left.20^{\circ} \mathrm{C}\right)$. Nevertheless, lower hydroperoxide concentrations $(\mathrm{PV}<10$ meq/kg oil after 50 days storage at $20{ }^{\circ} \mathrm{C}$ ) were obtained for Serfert et al. (2009) for microcapsules with a shell matrix composed of n-OSA starch and glucose syrup (fish oil load of $40 \mathrm{wt} . \%$ ), which were stabilized with specific combinations of natural antioxidants $(\alpha$ - and $\delta$-tocopherols, ascorbyl palmitate, citric acid, lecithin or citrem and rosemary extract). In line with PV results, the concentration of secondary volatile oxidation products was also higher for capsules with oil emulsified by high-pressure homogenization compared to capsules where the oil was emulsified using only a rotor-stator equipment (Fig. 7). For instance, significantly lower concentration of 1-penten-3-ol during storage was observed for G-RSE capsules compared to G-HPH capsules (Fig. 7a). Similarly, D-RSE and G-RSE showed a lower content of $(E)$-2-pentenal up to 14 days of storage than D-HPH and GHPH capsules, respectively (Fig. 7b). Both 1-penten-3-ol and (E)-2-pentenal are volatiles derived from the oxidation of omega-3 PUFA and they have low odour threshold values (0.001-3 ppm and 0.04-25 ppm, respectively) and undesired sensory attributes (milky, butter and sweet or oily, soapy, pungent, glue, green and grassy, respectively) (Hartvigsen et al. 2001; Venkateshwarlu et al. 2004). Likewise, lower content of volatiles products derived from oxidation of omega-9 fatty acids (i.e. heptanal and nonanal) were also found for D-RSE and G-RSE capsules compared to D-HPH and G-HPH capsules (Fig. 7c,d). Both heptanal and nonanal have also low odour threshold values (0.014-1 ppm) and unacceptable sensory characteristics for the consumer such as chemical and burnt or green plant-like, 
higher EE values when compared to D-HPH and G-HPH capsules, respectively (Table 2). Oil on the surface of the capsules oxidized rapidly due to the lack of protection by any interfacial layer of biopolymers, which implies that a larger amount of surface oil might have reduced the oxidative stability of D-HPH and G-HPH capsules (Drusch et al., 2007). Furthermore, the parent emulsions of D-RSE and G-RSE capsules were produced in situ in the pilot plant just right before electrospraying, which reduced the time elapsed from emulsification to drying and minimized physical destabilization of the emulsions. On the contrary, a more pronounced physical destabilization was observed in the parent emulsions of D-HPH and G-HPH capsules (Table 2), which may have led to unprotected oil droplets by modification of the interfacial layer.

Although no significant effect of the shell matrices evaluated (dextran vs. glucose syrup) was observed in PV (Fig. 6b), significant differences were found in terms of secondary volatile oxidation products (Fig. 7). In general, glucose capsules showed a significantly $(\mathrm{p}<0.05)$ lower concentration of volatiles compared to dextran capsules. This trend was clearly observed for: i) 1-penten-3-ol when comparing D-RSE and G-RSE capsules up to day 14 of storage (Fig. 7b), and iii) heptanal when comparing DHPH and G-HPH capsules at day 21 of storage, or D-RSE and G-RSE capsules up to 14 days of storage. An opposite trend was found for nonanal, with glucose syrup capsules presenting a higher concentration of this volatile during storage (Fig. 7d). However, this is attributed to the higher content of pullulan in glucose syrup capsules (4 wt.\%) compared to dextran capsules (1wt.\%), since pure pullulan electrospun fibers have been reported to present high concentration of nonanal (GarcíaMoreno et al., 2017a). These results indicated that the highest oxidative stability of G-RSE capsules cannot be solely explained by their extractable oil content, since D-RSE capsules presented significantly $(\mathrm{p}<0.05)$ higher EE values than G-RSE capsules (Table 2). This is in agreement with previous studies in the literature which indicated that: i) extractable oil also contains oil droplets surrounded by interfacial layer, which could offer some protection against oxidation (Drusch et al., 2007), and ii) surface oil could protect other fractions of the extractable oil from oxidation (e.g. oil 
fish oil in microcapsules by spray-drying stated the importance of oxygen diffusivity on autooxidation of omega-3 PUFA (Drusch et al., 2009). Therefore, a plausible explanation for the higher oxidative stability of G-RSE compared to D-RSE might be the result of a reduced free volume for the glucose syrup matrix compared to the dextran shell. Glucose syrup had a lower molecular weight than dextran (12.5 vs. $70 \mathrm{kDa}$ ), which may allow a more dense packaging within the glassy wall, limiting oxygen permeability; and thus, reducing oil oxidation. Similarly, Drusch et al. (2009) demonstrated the presence of larger free volume elements for glassy carbohydrates matrices with higher molecular weight, which correlated well with the lower oxidative stability of fish oil encapsulated in these matrices (i.e. maltodextrin with DE 18 and maltose with estimated DE 50). Therefore, the authors suggested that the reduced oxygen diffusivity in fish oil-loaded microcapsules containing low molecular weight carbohydrates (e.g. maltose with estimated DE 50) explained the enhanced oxidative stability of these capsules.

\section{CONCLUSIONS}

Biopolymer solutions containing fish oil (20 wt.\% with respect to biopolymers), WPC (0.5 wt.\%), citrem (0.5 wt.\%), and pullulan (1wt.\%) plus dextran (15wt.\%) or pullulan (4wt.\%) plus glucose syrup (15 wt.\%) led to electrosprayed capsules without any fibril defects, both when producing in lab and pilot-plant scale. To the best of the authors' knowledge, this is the first study reporting the production of electrosprayed capsules by using combinations of whey protein and carbohydrates. Moreover, electrosprayed capsules were developed for the first time by using glucose syrup as the main wall material. This is of special importance due to the low cost of this biopolymer.

The ATR-FTIR method was not sensitive enough to study oxidative stability of the fish oil-loaded capsules, since no changes in the normalized absorbance of the band at $3012 \mathrm{~cm}^{-1}$ (indicating the stretching of cis-alkene $-\mathrm{HC}=\mathrm{CH}-$ groups) was observed during storage. Nevertheless, the 500 hydroperoxide and volatiles content of the capsules increased during storage. Capsules with oil 
503 volatiles (1-penten-3-ol, (E)-2-pentenal, heptanal, and nonanal) content. This was explained by a 504 higher encapsulation efficiency and a shorter time span between emulsification and drying which 505 reduced physical destabilization of emulsions. Glucose syrup capsules presented higher oxidative 506 stability than dextran capsules. This finding was attributed to the lower molecular weight of glucose 507 syrup, which led to lower free volume in the glassy matrix reducing oxygen diffusivity. Finally, it has 508 to be mentioned that the oxidative stability of the electrosprayed capsules needs to be further improved 509 (i.e. by reducing surface oil).

\section{ACKNOWLEDGEMENTS}

511 This work was supported by the European Commission (ELECTRONANOMEGA project). P.J. 512 García-Moreno acknowledges a Marie-Curie postdoctoral fellowship (Grant Agreement 654818). The 513 authors would also like to thank Terje Svingen and Liyun Yu for their help with the fluorescence 514 microscopy and DSC measurements, respectively.

\section{REFERENCES}

Adjonu, R., Doran, G., Torley, P., \& Agboola, S. (2014). Whey protein peptides as

components of nanoemulsions: A review of emulsifying and biological functionalities. Journal of

Food Engineering, 122, 15-27.

Aghbashlo, M., Mobli, H., Madadlou, A., \& Rafiee, S. (2012). The correlation of wall material composition with flow characteristics and encapsulation behavior of fish oil emulsion. Food Research International, 49, 379-388.

AOCS (1998a). AOCS Official Method Ce 2e66. Preparation of Methyl Esters of Long Chain Fatty Champaign: AOCS Press. AOCS (1998b). AOCS Official Method Ce 1be89. Fatty Acid Composition by GLC, Marine

Oils. Champaign: AOCS Press. 
529 Ingredients. In A. G. Gaonkar, N. Vasisht, A. R. Khare \& R. Sobe (Eds.), Microencapsulation in the 530 Food Industry - A Practical Implementation Guide (pp. 211-226). Elsevier Inc., London.

Canadian Journal of Biochemistry and Physiology, 37, 911-917.

efficiency and oxidative stability of flaxseed oil microencapsulated by spray drying using different combinations of wall materials. Journal of Food Engineering, 115, 443-451.

Drosou, C. G., Krokida, M. K., \& Biliaderis, C. G. (2017). Encapsulation of bioactive compounds through electrospinning/electrospraying and spray drying: A comparative assessment of food-related applications. Drying Technology, 35, 139-162.

Drusch, S., Serfert, Y., \& Schwarz, K. (2006). Microencapsulation of fish oil with noctenylsuccinate-derivatised starch: Flow properties and oxidative stability. European Journal of Lipid Science and Technology, 108, 501-512.

Drusch, S. (2007). Sugar beet pectin: A novel emulsifying wall component for microencapsulation of lipophilic food ingredients by spray-drying. Food Hydrocolloids, 21, 12231228.

Drusch, S., Serfert, Y., Scampicchio, M., Schmidt-Hansberg, B., \& Schwarz, K. (2007). Impact of physicochemical characteristics on the oxidative stability of fish oil microencapsulated by spray-drying. Journal of Agricultural and Food Chemistry, 55, 11044-11051.

Drusch, S., \& Berg, S. (2008). Extractable oil in microcapsules prepared by spraydrying: Localisation, determination and impact on oxidative stability. Food Chemistry, 109, 17-24. 
555 Conventional spray-drying and future trends for the microencapsulation of fish oil. Trends in Food 556 Science \& Technology, 56, 46-60.

Fathi, M., Martín, T., \& McClements, D. J. (2014). Nanoencapsulation of food ingredients using carbohydrate based delivery systems. Trends in Food Science and Technology, 39, 18-39.

García Moreno, P. J., Boutrup Stephansen, K., van derKruijs, J., Guadix, A., Guadix, E. M.,

Chronakis, I. S., \& Jacobsen, C. (2016). Encapsulation of fish oil in nanofibers by emulsion electrospinning: Physical characterization and oxidative stability. Journal of Food Engineering, 183, 39-49.

García-Moreno, P. J., Özdemir, N., Stephansen, K., Mateiu, R. V., Echegoyen, Y., Lagaron, J. M., Chronakis, I.S., Jacobsen, C. (2017a). Development of carbohydrate-based nano-microstructures loaded with fish oil by using electrohydrodynamic processing. Food Hydrocolloids, 69, 273-285.

García-Moreno, P. J., Damberg, C., Chronakis, I. S., \& Jacobsen, C. (2017b). Oxidative stability of pullulan electrospun fibers containing fish oil: Effect of oil content and natural antioxidants addition. European Journal of Lipid Science and Technology, 119, 1600305.

Ghorani, B., \& Tucker, N. (2015). Fundamentals of electrospinning as a novel delivery vehicle for bioactive compounds in food nanotechnology. Food Hydrocolloids, 51, 227-240.

GOED

(2015).

GOED Publishes Finished Product

Report.

URL (http://goedomega3.com/index.php/news/newslist) (accessed July 2017). micro- and submicroparticles for the encapsulation and stabilization of thermosensitive hydrophobic bioactives. Journal of Colloid and Interface Science, 465, 259-270.

Guillén, M. D., \& Cabo, N. (1999). Usefulness of the frequency data of the fourier transform 
580 transform infrared spectra of edible oils under oxidative conditions. Journal of the Science of Food 581 and Agriculture, 80, 2028-2036.

Hartman, R. P. A., Brunner, D. J., Camelot, D. M. A., Marijnissen, J. C. M., \& Scarlett, B.

(2000). Jet break-up in electrohydrodynamic atomization in the cone-jet mode. Journal of Aerosol

Science, 31, 65-95.

Hartvigsen, K., Lund, P., Hansen, L. F., \& Holmer, G. (2000). Dynamic headspace gas

chromatography/mass spectrometry characterization of volatiles produced in fish oil enriched mayonnaise during storage. Journal of Agricultural and Food Chemistry, 48, 4858-4867.

Hu, M. 2016. Oxidative Stability and Shelf Life of Low-Moisture Foods. In M. Hu \& C. Jacobsen (Eds.), Oxidative Stability and Shelf Life of Foods Containing Oils and Fats (pp. 313-371). AOCS Press, London.

Huang, H., Hao, S., Li, L., Yang, X., Cen, J., Lin, W., \& Wei, Y. (2014). Influence of emulsion composition and spray-drying conditions on microencapsulation of tilapia oil. Journal of Food Science and Technology, 51, 2148-2154.

Jacobsen, C. (2015). Some strategies for the stabilization of long chain n-3 PUFA-enriched foods: A review. European Journal of Lipid Science and Technology, 117, 1853-1866.

Jacobsen, C., García-Moreno, P. J., Mendes, A. C., Mateiu, R. V., \& Chronakis, I.S. (2018).

Use of electrohydrodynamic processing for encapsulation of sensitive bioactive compounds and applications in food. Annual Review of Food Science and Technology. In press.

Lim, L. T. (2015). Encapsulation of bioactive compounds using electrospinning and electrospraying technologies. In Sabliov CM, Chen H, Yada RY (Eds.), Nanotechnology and 601 Functional Foods: Effective Delivery of Bioactive Ingredients (pp. 297-317). John Wiley \& Sons, 602 New York. 
properties of electrospun zein fibres. Food Hydrocolloids, 46, 191-200.

Morales-Medina, R., Tamm, F., Guadix, A. M., Guadix, E. M., \& Drusch, S. (2016).

608 Functional and antioxidant properties of hydrolysates of sardine (S. pilchardus) and horse mackerel (T. 609 mediterraneus) for the microencapsulation of fish oil by spray-drying. Food Chemistry, 194, 12086101216.

Pérez-Masiá, R., Lagaron, J. M., \& López-Rubio, A. (2014). Development and optimization of 612 novel encapsulation structures of interest in functional foods through electrospraying. Food and 613 Bioprocess Technology, 7, 3236-3245.

Pérez-Masiá, R., Lagaron, J. M., \& López-Rubio, A. (2015). Morphology and stability of 615 edible lycopene-containing micro- and nanocapsules produced through electrospraying and spray 616 drying. Food and Bioprocess Technology, 8, 459-470.

Ramakrishnan, S., Ferrando, M., Aceña-Muñoz, L., De Lamo-Castellví, S., \& Güell, C. (2013). 618 Fish oil microcapsules from $\mathrm{O} / \mathrm{W}$ emulsions produced by premix membrane emulsification. Food and 619 Bioprocess Technology, 6, 3088-3101.

620 Scandola, M., Ceccorulli, G., \& Pizzoli, M. (1991). Molecular motions of polysaccharides in 621 the solid state: Dextran, pullulan and amylose. International Journal of Biological Macromolecules, $622 \quad 13,254-260$. polyunsaturated fatty acids during homogenisation, microencapsulation and storage. Food Chemistry, $113,1106-1112$.

Schutyser, M. A. I., Perdana, J., \& Boom, R. M. (2012). Single droplet drying for optimal spray drying of enzymes and probiotics. Trends in Food Science and Technology, 27, 73-82.

Shahidi, F. (2001). Headspace volatile aldehydes as indicators of lipid oxidation in foods. Advances in Experimental Medicine and Biology, 488, 113-123. 
631 methods for determination of peroxide values of food lipids. Journal of AOAC International, 77, $632421-424$.

633 Tamm, F., Herbst, S., Brodkorb, A., \& Drusch, S. (2016). Functional properties of pea protein 634 hydrolysates in emulsions and spray-dried microcapsules. Food Hydrocolloids, 58, 204-214.

635 Torres-Giner, S., Martinez-Abad, A., Ocio, M. J., \& Lagaron, J. M. (2010). Stabilization of a 636 nutraceutical omega-3 fatty acid by encapsulation in ultrathin electrosprayed zein prolamine. Journal 637 of Food Science, 75, N69-N79.

638 Venkateshwarlu, G., Let, M. B., Meyer, A. S., \& Jacobsen, C. (2004). Chemical and 639 olfactometric characterization of volatile flavor compounds in a fish oil enriched milk emulsion. 640 Journal of Agricultural and Food Chemistry, 52, 311-317.

641 Westergaard, V. (2004). Milk powder technology: Evaporation and spray drying. Niro A/S, 642 Copenhagen. 
Table 1. Oil droplet size and electrospraying flow rate for the different biopolymers solutions

\begin{tabular}{|c|c|c|c|c|}
\hline & \multirow{2}{*}{ Solutions } & \multicolumn{2}{|c|}{ Oil droplet size, $\mu \mathrm{m}$} & \multirow{2}{*}{$\begin{array}{l}\text { Electrospraying flow } \\
\text { rate, } \mathrm{mL} / \mathrm{min}\end{array}$} \\
\hline & & $\mathbf{D}_{3,2}$ & $\mathrm{D}_{0,9}$ & \\
\hline \multirow{5}{*}{ Dextran } & $1 \% \mathrm{WPC}+2 \%$ pullulan $+20 \%$ dextran & $0.684^{a}$ & $1.894^{\mathrm{a}}$ & 0.012 \\
\hline & $1 \%$ WPC $+2 \%$ pullulan $+15 \%$ dextran & $0.327^{b}$ & $1.009^{b}$ & 0.012 \\
\hline & $1 \%$ WPC $+1 \%$ pullulan $+20 \%$ dextran & $0.600^{\mathrm{a}, *}$ & $1.647^{\mathrm{a}, *}$ & 0.010 \\
\hline & $1 \%$ WPC $+1 \%$ pullulan $+15 \%$ dextran & $0.280^{\mathrm{b}, *}$ & $0.909^{\mathrm{b}, *}$ & 0.010 \\
\hline & $\begin{array}{l}0.5 \% \text { WPC }+0.5 \% \text { citrem }+1 \% \text { pullulan }+ \\
15 \% \text { dextran }\end{array}$ & $0.129^{\dagger}$ & $0.334^{\dagger}$ & 0.010 \\
\hline \multirow{4}{*}{$\begin{array}{l}\text { Glucose } \\
\text { syrup }\end{array}$} & $1 \%$ WPC $+2 \%$ pullulan $+15 \%$ glucose syrup & $0.163^{\mathrm{a}}$ & $0.485^{\mathrm{a}}$ & 0.003 \\
\hline & $1 \%$ WPC+4\% pullulan $+15 \%$ glucose syrup & $0.189^{b}$ & $0.581^{b}$ & 0.007 \\
\hline & $1 \%$ WPC $+5 \%$ pullulan $+15 \%$ glucose & $0.212^{c}$ & $0.614^{c}$ & 0.010 \\
\hline & $\begin{array}{l}0.5 \% \text { WPC }+0.5 \% \text { citrem }+4 \% \text { pullulan }+ \\
15 \% \text { glucose syrup }\end{array}$ & $0.112^{\dagger}$ & $0.259^{\dagger}$ & 0.007 \\
\hline
\end{tabular}

Standard deviatons for oil droplet size measurements were $<0.008 \mu \mathrm{m}$. No deviations were observed for flow rate.

For dextran samples, different letters $(a-b)$ indicate statistical significant differences $(p<0.05)$ between samples containing different concentration of dextran but same concentration of pullulan. ${ }^{*}$ indicates statistical significant differences $(p<0.05)$ between samples with same dextran concentration but different concentration of pullulan. For glucose syrup samples, different letters $(a-b)$ indicate statistical significant differences $(p<0.05)$ between samples containing different concentration of pullulan.

t indicates statistical significant differences $(p<0.05)$ between samples with and without citrem. 
Table 2. Oil droplet size of redispersed nano-microcapsules and encapsulation efficiency

\begin{tabular}{ccccc}
\hline \multirow{2}{*}{ Electrosprayed capsules } & \multicolumn{2}{c}{ Oil droplet size, $\mu \mathrm{m}$} & \multirow{2}{*}{ Encapsulation efficiency (EE), \% } \\
\cline { 2 - 4 } & & $\mathbf{D}_{3,2}$ & $\mathbf{D}_{0,9}$ & \\
\hline \multirow{2}{*}{ Dextran } & $\mathrm{HPH}$ & $0.414 \pm 0.013^{\mathrm{a}}$ & $1.762 \pm 0.102^{\mathrm{a}}$ & $86.9 \pm 1.5^{\mathrm{a}}$ \\
\cline { 2 - 4 } & $\mathrm{RSE}$ & $0.388 \pm 0.006^{\mathrm{b}}$ & $2.548 \pm 0.176^{\mathrm{b}}$ & $91.7 \pm 0.9^{\mathrm{b}}$ \\
\hline \multirow{2}{*}{ Glucose syrup } & $\mathrm{HPH}$ & $0.605 \pm 0.009^{\mathrm{x},{ }^{*}}$ & $3.008 \pm 0.079^{\mathrm{x},{ }^{*}}$ & $78.1 \pm 3.2^{\mathrm{x},{ }^{*}}$ \\
\cline { 2 - 4 } & $\mathrm{RSE}$ & $0.461 \pm 0.061^{\mathrm{y}, \mathrm{ns}}$ & $3.960 \pm 0.355^{\mathrm{y}, \dagger}$ & $85.7 \pm 0.3^{\mathrm{y}, \dagger}$ \\
\hline
\end{tabular}

HPH: high-pressure homogenization; RSE: rotor-stator emulsification

Letters $(a-b)$ indicate statistical significant differences $(p<0.05)$ between dextran samples.

Letters $(x-y)$ indicate statistical significant differences $(p<0.05)$ between glucose syrup samples.

* indicates significant differences $(p<0.05)$ between dextran and glucose samples with oil emulsified by highpressure homogenization.

ns indicates no significant differences $(p>0.05)$ between dextran and glucose samples with oil emulsified by rotor-stator emulsification.

$\dagger$ indicates significant differences $(p<0.05)$ between dextran and glucose samples with oil emulsified by rotorstator emulsification. 
a)

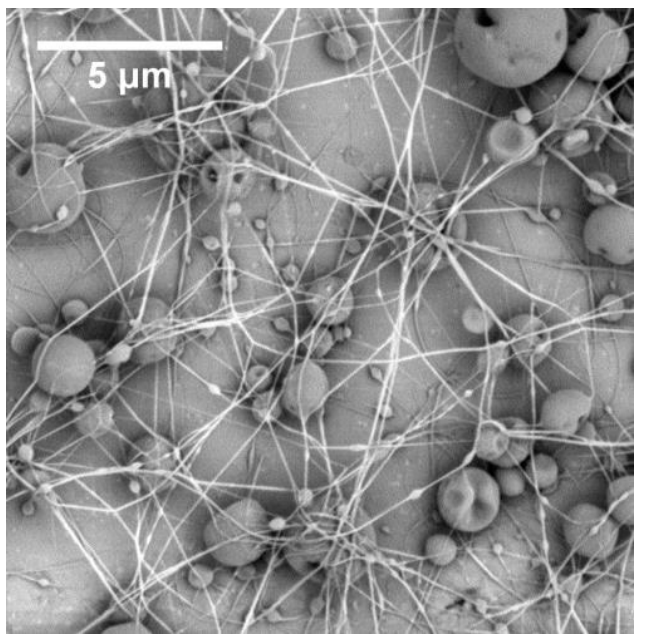

c)

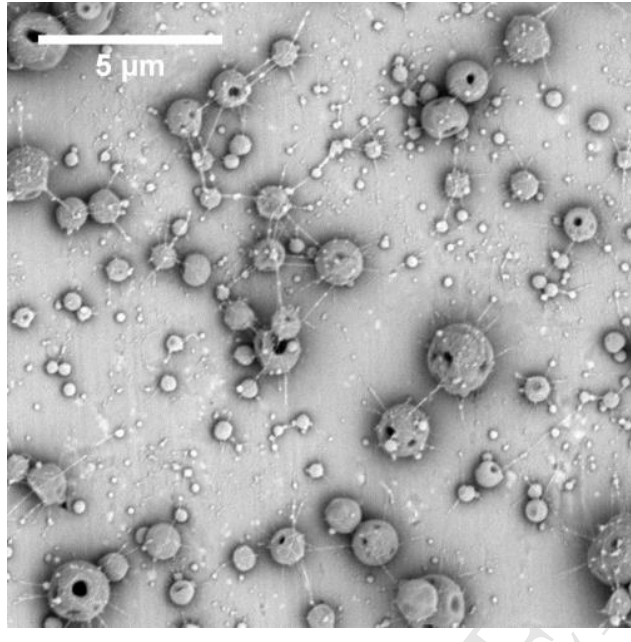

b)

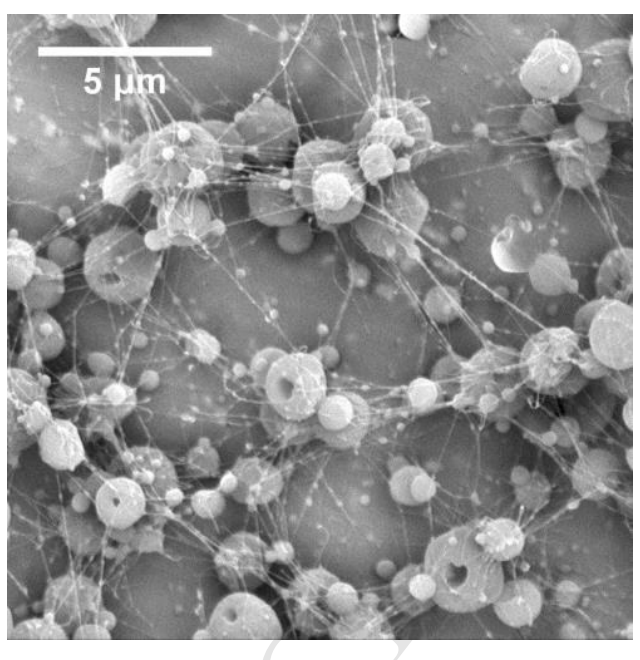

d)

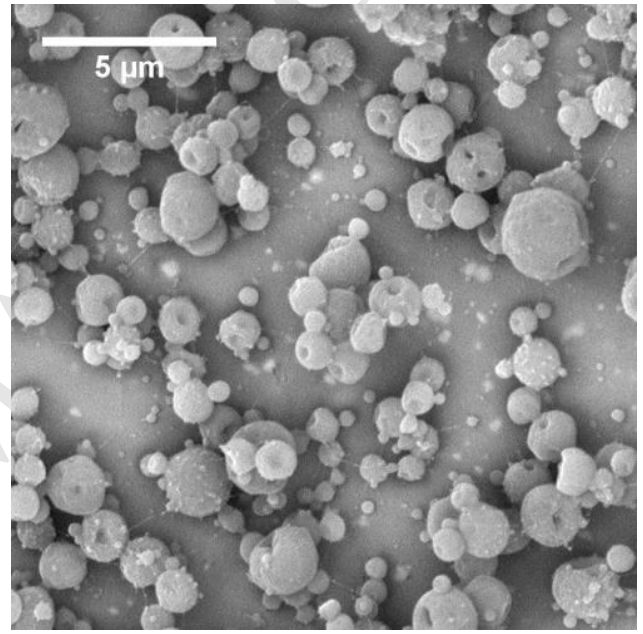

Figure 1. SEM images of nano-microstructures obtained by electrospraying of WPC (1 wt.\%), pullulan and dextran solutions containing emulsified fish oil $(20 \mathrm{wt} \%$ oil with respect to biopolymers): (a) 2 wt. $\%$ pullulan +20 wt. $\%$ dextran, (b) 2 wt. $\%$ pullulan +15 wt. $\%$ dextran, (c) 1 wt. $\%$ pullulan $+20 \mathrm{wt} . \%$ dextran, and (d) $1 \mathrm{wt} . \%$ pullulan $+15 \mathrm{wt} . \%$ dextran. 
a)

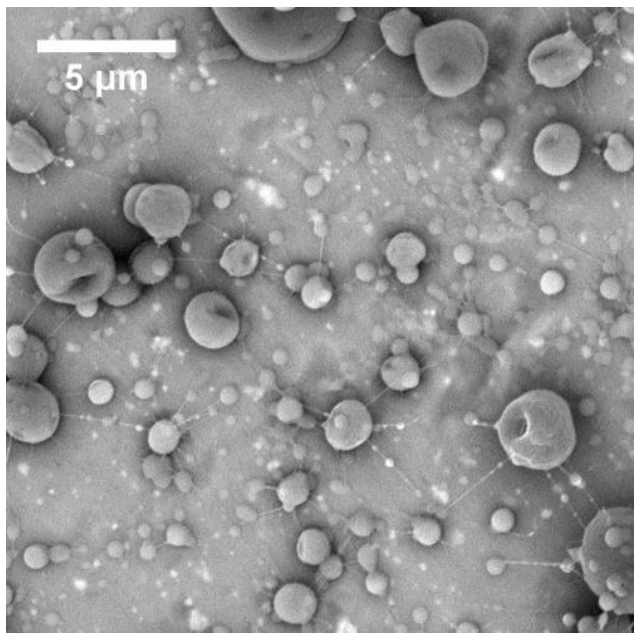

b)

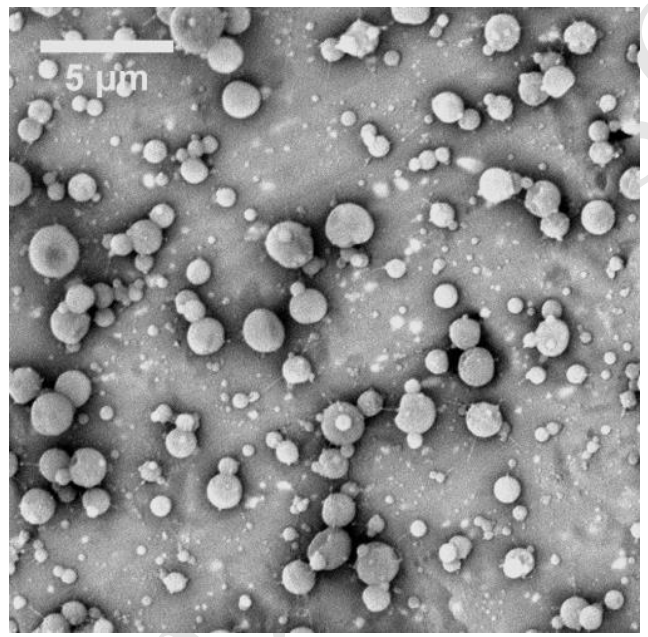

c)

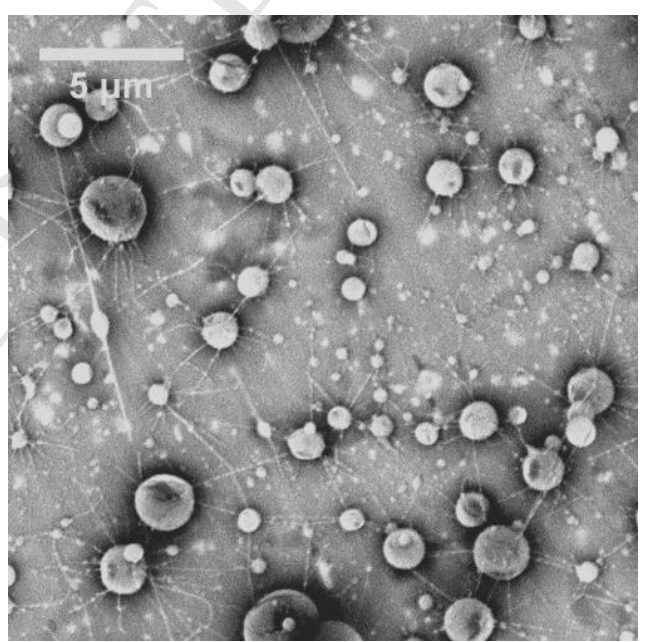

Figure 2. SEM images of nano-microstructures obtained by electrospraying of WPC (1 wt.\%), pullulan and glucose syrup (15 wt.\%) solutions containing emulsified fish oil (20 wt.\% oil with respect to biopolymers): (a) $2 \mathrm{wt} . \%$ pullulan, (b) $4 \mathrm{wt} . \%$ pullulan, and (c) $5 \mathrm{wt} . \%$ pullulan. 


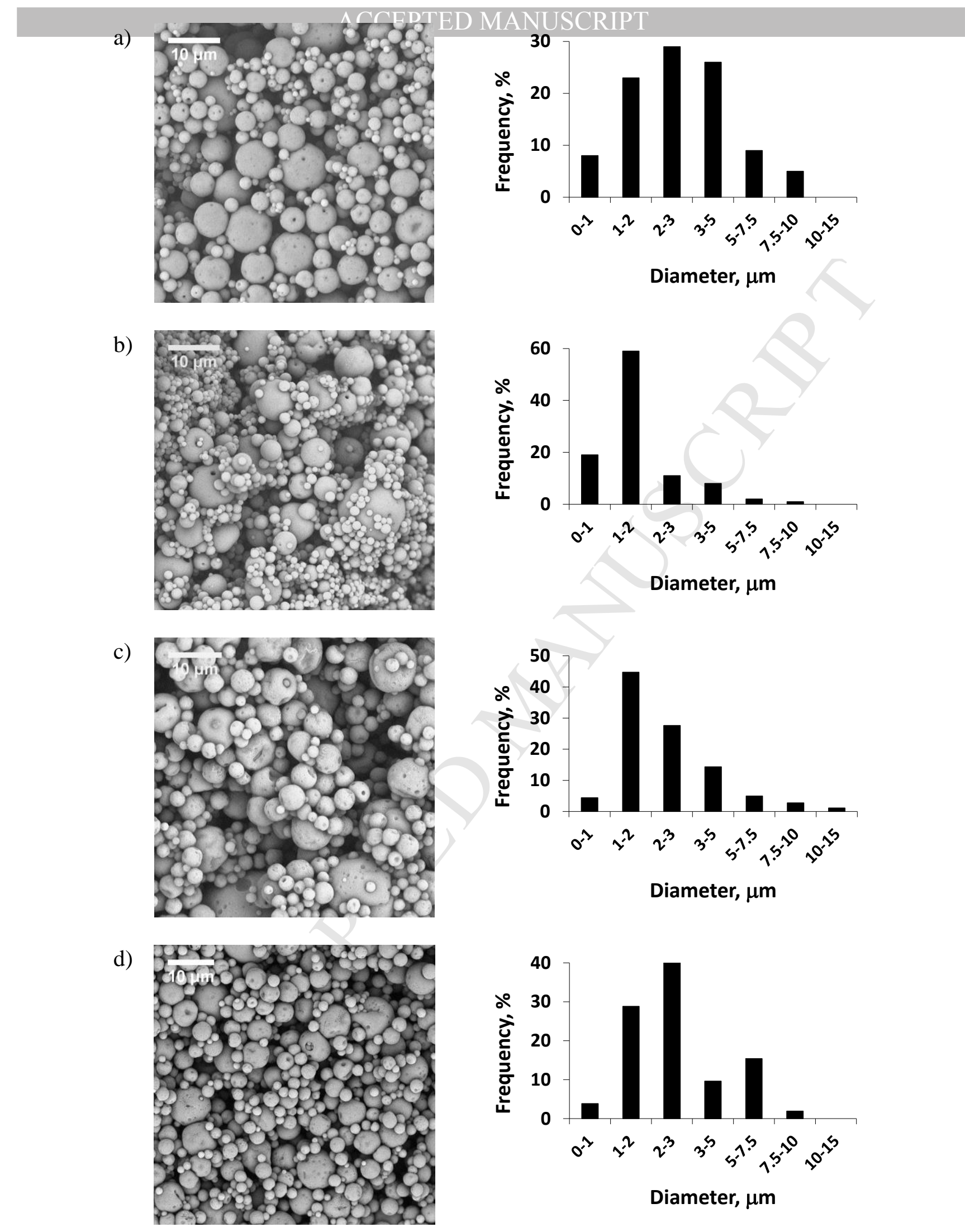

Figure 3. SEM images and diameter distribution of electrosprayed capsules: (a) D-HPH, (b) D-RSE, (c) G-HPH, and (d) G-RSE.

D: dextran; G: glucose syrup; HPH: high-pressure homogenization; RSE: rotor-stator emulsification. 


\section{ACCEPTED MANUSCRIPT}

a1)

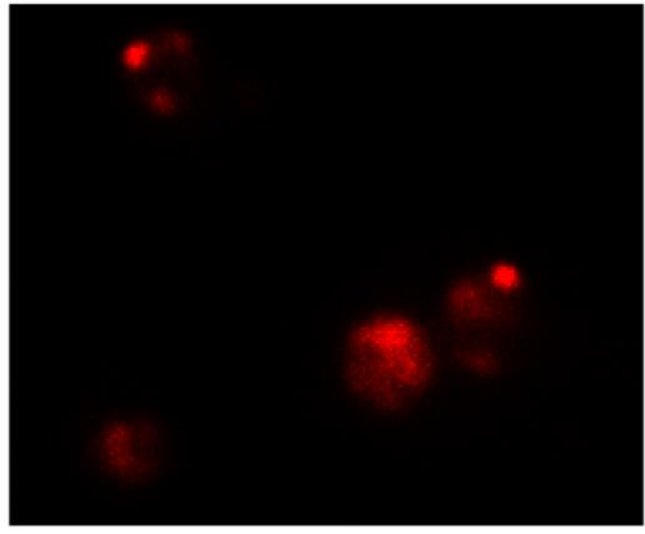

a2)

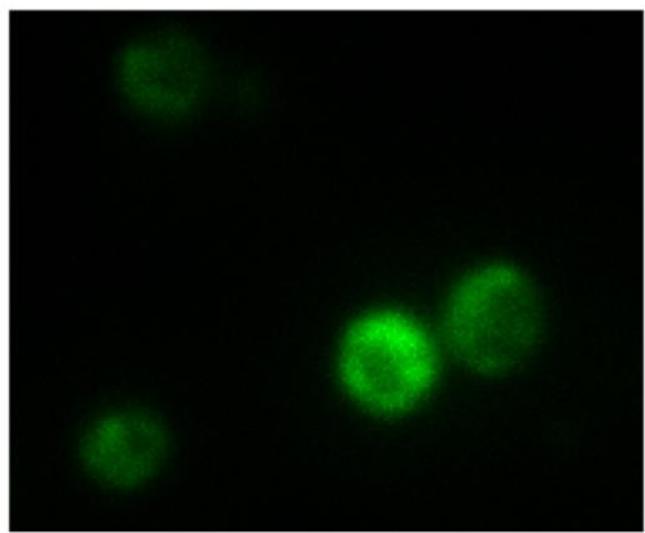

a3)

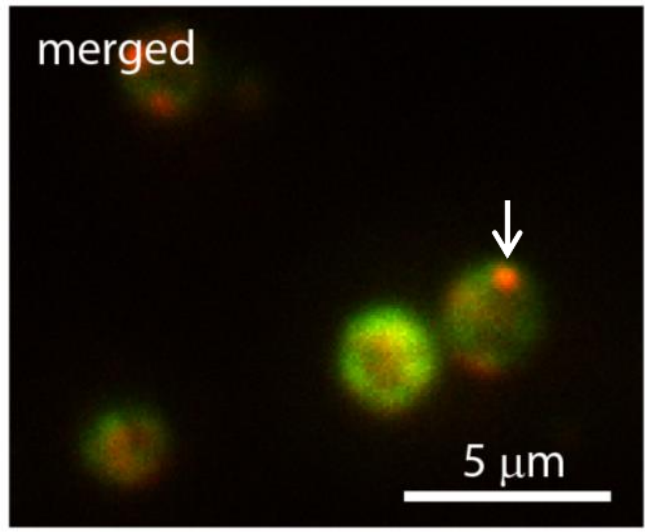

b1)

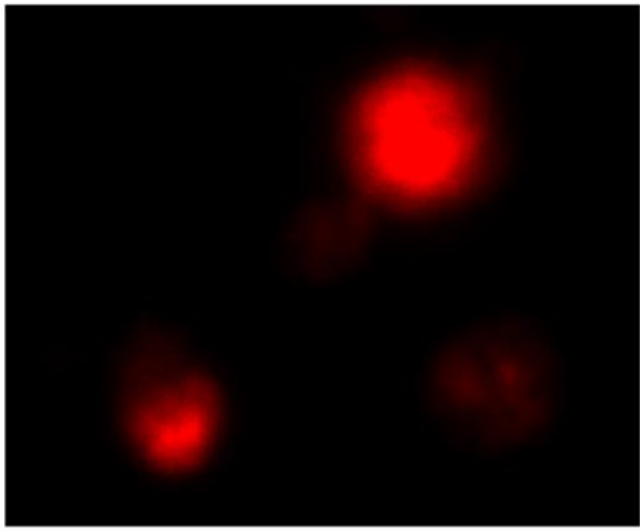

b2)

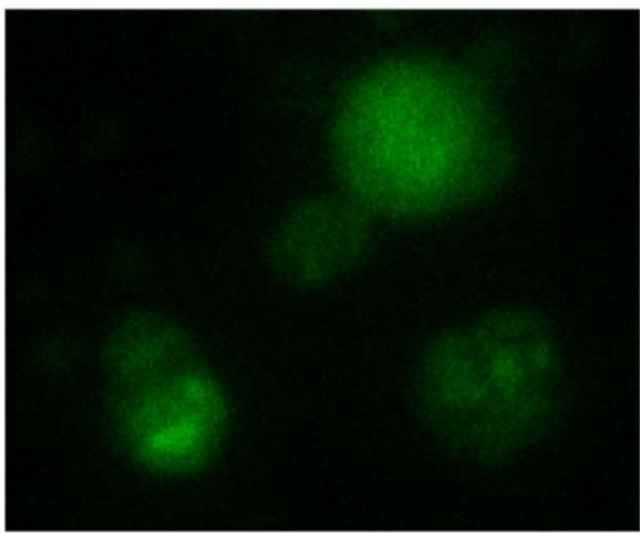

b3)

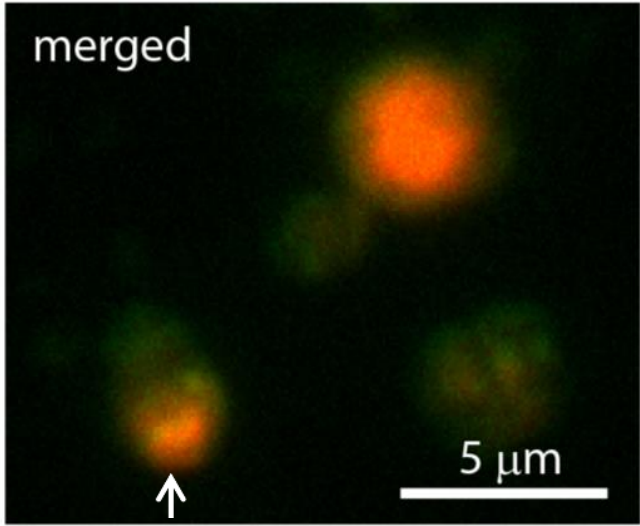

Figure 4. Fluorescence microcopy images of electrosprayed capsules produced in lab scale using highpressure homogenization for incorporating the oil: a) dextran-based capsules, and b) glucose syrupbased capsules. a1) and b1) show the location of fish oil (in red); a2) and b2) show the location of WPC (in green); and a3) and b3) show the simultaneous location of fish oil and WPC. 
a)

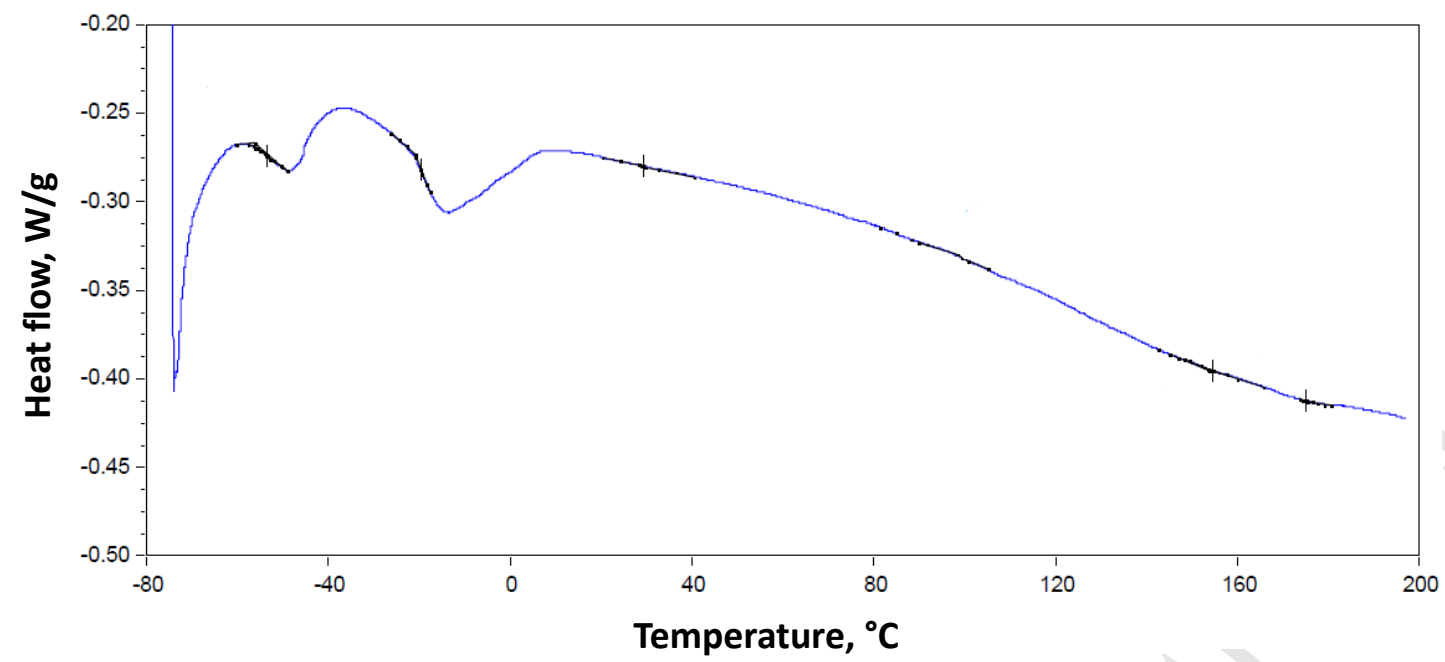

b)

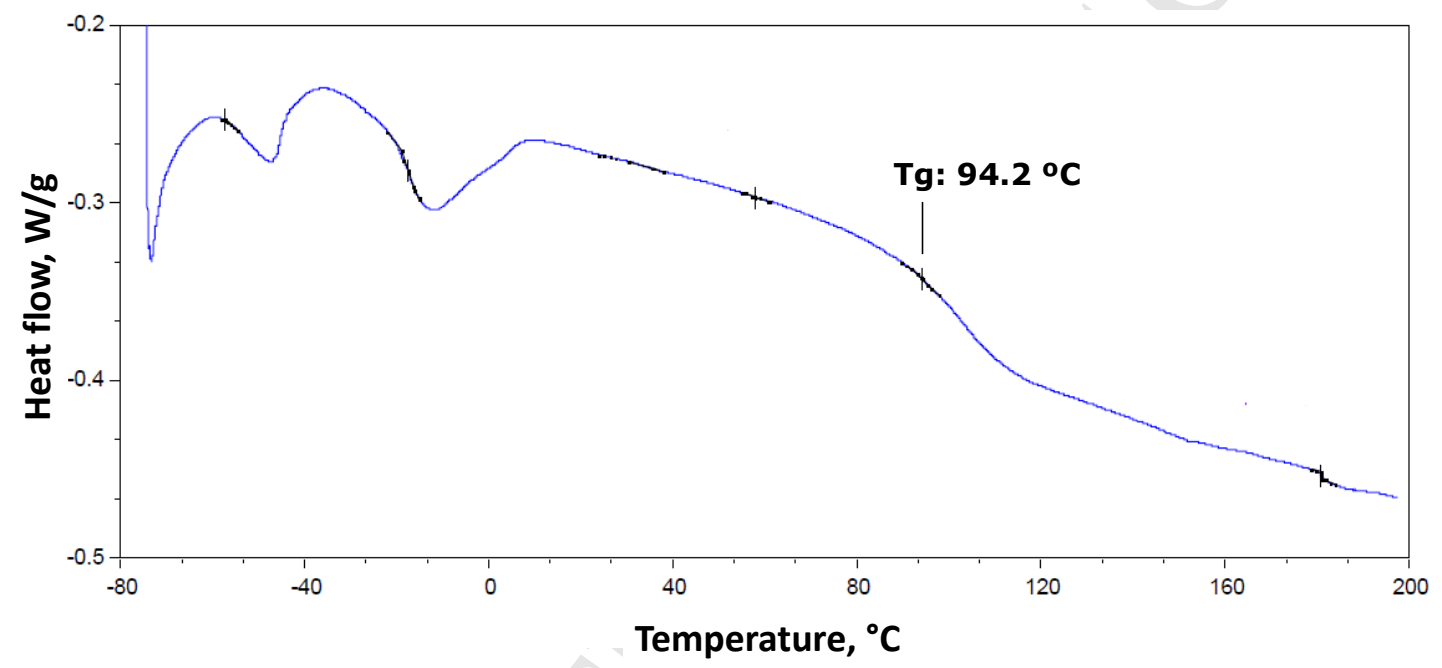

Figure 5. DSC heating curves of electrosprayed capsules produced in pilot-plant scale using highpressure homogenization for incorporating the oil: a) dextran-based capsules, and b) glucose syrupbased capsules. 
a)
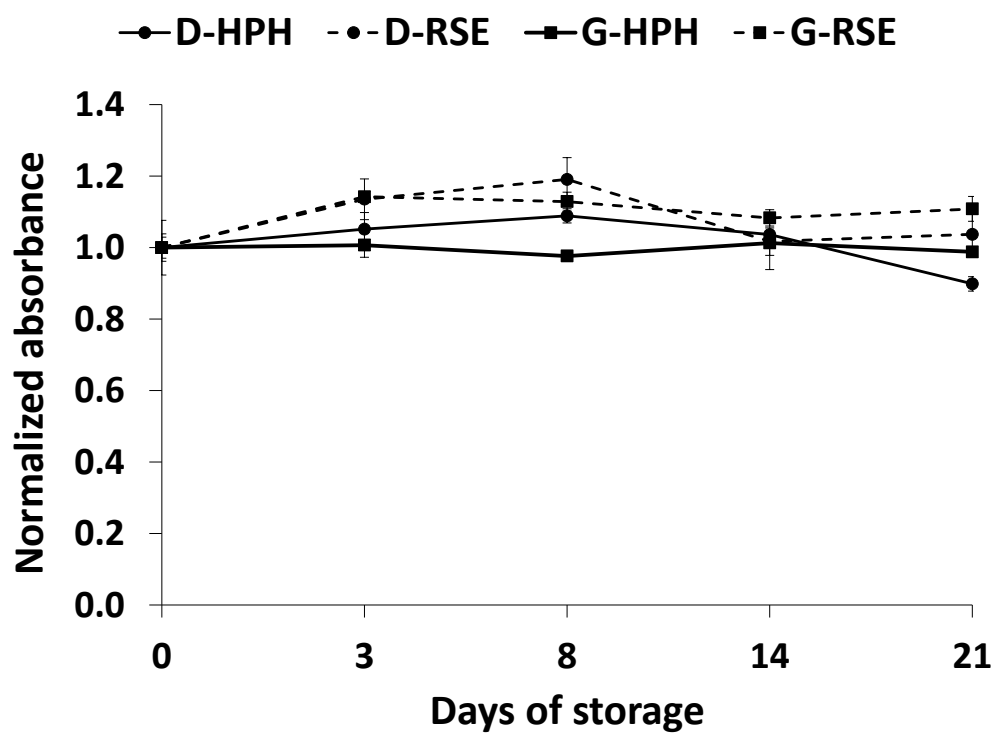

b)

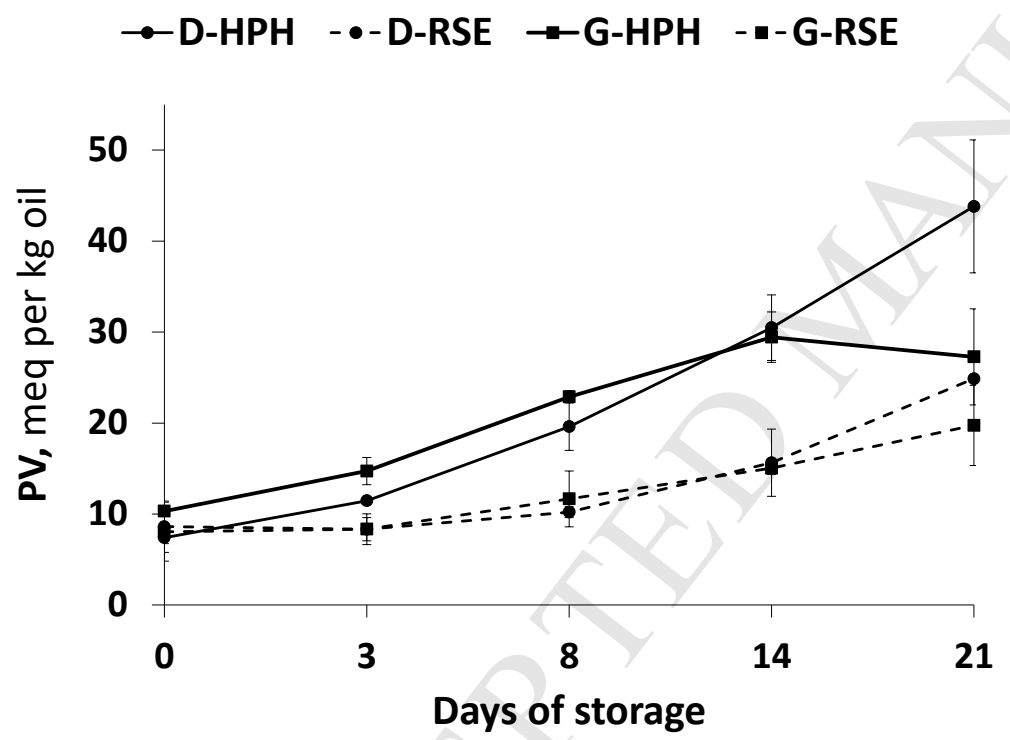

Figure 6. Oxidative stability of electrosprayed capsules loaded with fish oil during storage at $20{ }^{\circ} \mathrm{C}$ : a) ATR-FTIR, and b) Peroxide value (PV).

D: dextran; G: glucose syrup; HPH: high-pressure homogenization; RSE: rotor-stator emulsification 
a)

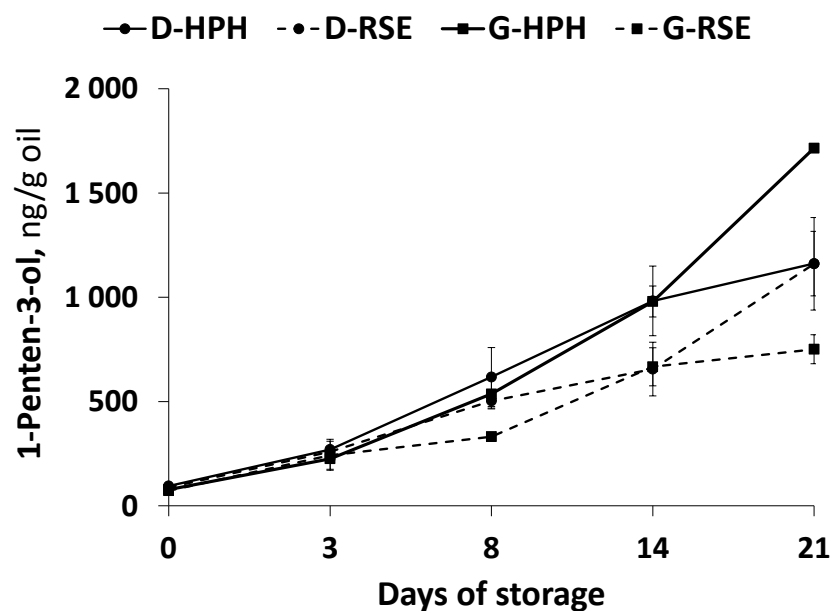

c)

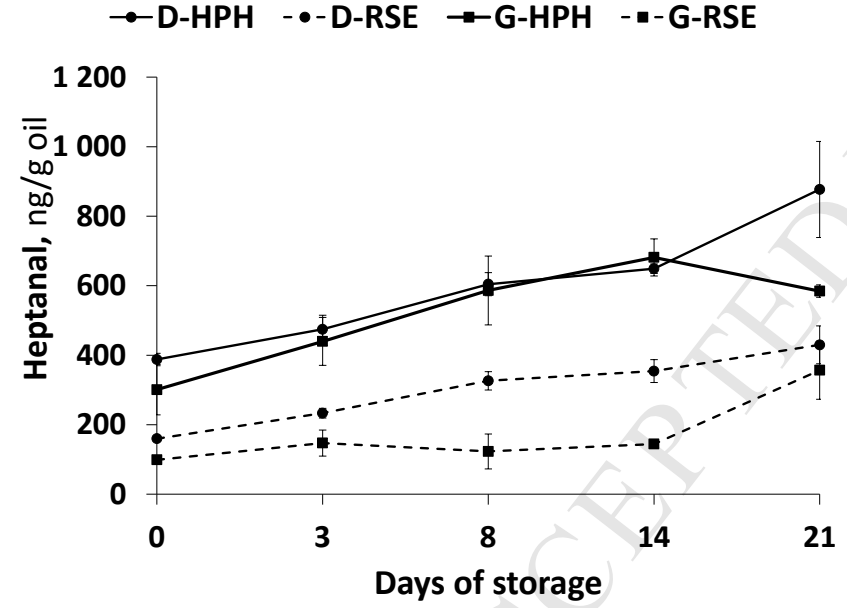

b)

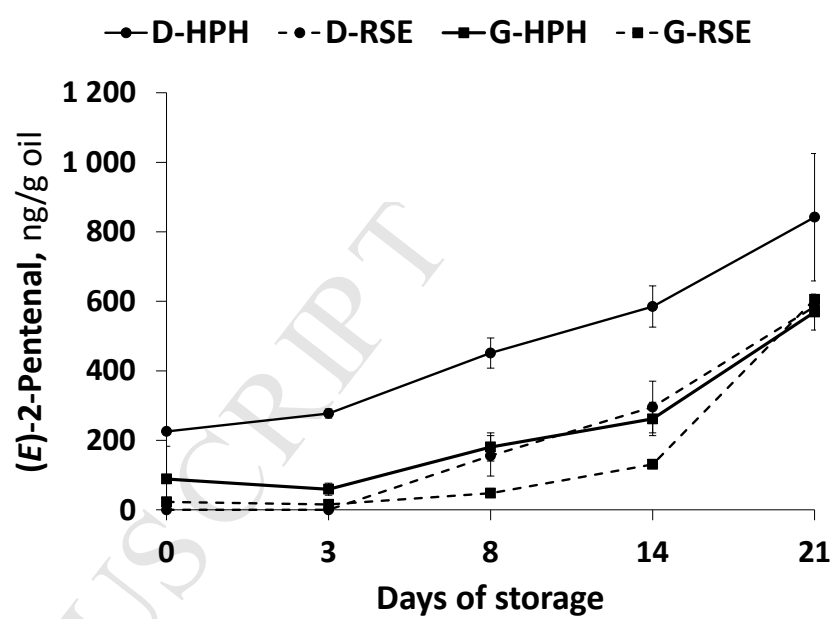

d)

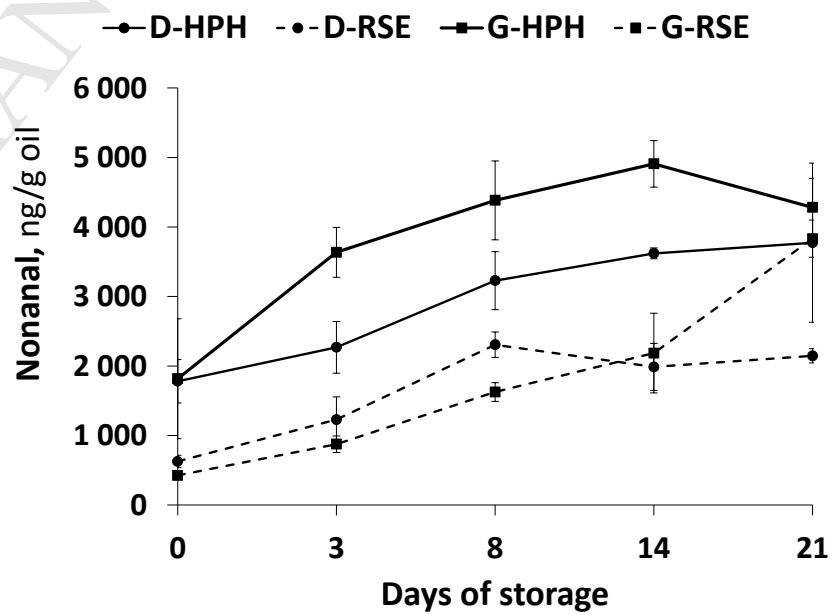

Figure 7. Secondary volatiles oxidation products of electrosprayed capsules loaded with fish oil during storage at $20^{\circ} \mathrm{C}$ : a) 1-penten-3-ol, b) D: dextran; G: glucose syrup; HPH: high-pressure homogenization; RSE: rotor-stator emulsification. 


\section{Highlights}

- Fish oil-loaded nano-microcapsules were produced by electrospraying

- Whey protein, pullulan and dextran or glucose syrup were used as wall materials

- Rotor-stator emulsification led to capsules with higher oxidative stability

- The glucose syrup matrix prevented more efficiently oxidation of encapsulated oil

- Electrosprayed capsules are promising omega-3 nano-delivery systems 